\title{
The contribution of eastern-boundary density variations to the Atlantic meridional overturning circulation at $26.5^{\circ} \mathrm{N}$
}

\author{
M. P. Chidichimo ${ }^{1,2}$, T. Kanzow ${ }^{3,4}$, S. A. Cunningham ${ }^{3}$, W. E. Johns ${ }^{5}$, and J. Marotzke ${ }^{1}$ \\ ${ }^{1}$ Ozean im Erdsystem, Max-Planck-Institut für Meteorologie, Bundesstraße 53, 20146 Hamburg, Germany \\ ${ }^{2}$ International Max Planck Research School on Earth System Modelling, Hamburg, Germany \\ ${ }^{3}$ Ocean Observation and Climate Group, National Oceanography Centre, Empress Dock, Southampton, SO17 3ZH, UK \\ ${ }^{4}$ Ozeanzirkulation und Klimadynamik, Leibniz-Institut für Meereswissenschaften an der Universität Kiel, Düsternbrooker \\ Weg 20, 24105 Kiel, Germany \\ ${ }^{5}$ Division of Meteorology and Physical Oceanography, Rosenstiel School of Marine and Atmospheric Science, 4600 \\ Rickenbacker Causeway, Miami, FL 33149-1098, USA
}

Received: 30 September 2009 - Published in Ocean Sci. Discuss.: 4 November 2009

Revised: 9 March 2010 - Accepted: 2 April 2010 - Published: 26 April 2010

\begin{abstract}
We study the contribution of eastern-boundary density variations to sub-seasonal and seasonal anomalies of the strength and vertical structure of the Atlantic Meridional Overturning Circulation (AMOC) at $26.5^{\circ} \mathrm{N}$, by means of the RAPID/MOCHA mooring array between April 2004 and October 2007. The major density anomalies are found in the upper $500 \mathrm{~m}$, and they are often coherent down to $1400 \mathrm{~m}$. The densities have 13-day fluctuations that are apparent down to $3500 \mathrm{~m}$. The two strategies for measuring eastern-boundary density - a tall offshore mooring (EB1) and an array of moorings on the continental slope (EBH) - show little correspondence in terms of amplitude, vertical structure, and frequency distribution of the resulting basin-wide integrated transport fluctuations, implying that there are significant transport contributions between EB1 and EBH. Contrary to the original planning, measurements from EB1 cannot serve as backup or replacement for EBH: density needs to be measured directly at the continental slope to compute the full-basin density gradient. Fluctuations in density at EBH generate transport variability of $2 \mathrm{~Sv}$ rms in the AMOC, while the overall AMOC variability is $4.8 \mathrm{~Sv}$ rms. There is a pronounced deep-reaching seasonal cycle in density at the eastern boundary, which is apparent between $100 \mathrm{~m}$ and $1400 \mathrm{~m}$, with maximum positive anomalies in spring and maximum negative anomalies in autumn. These changes
\end{abstract}

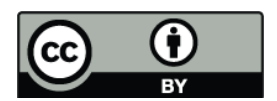

Correspondence to: M. P. Chidichimo (maria-paz.chidichimo@zmaw.de) drive anomalous southward upper mid-ocean flow in spring, implying maximum reduction of the AMOC, and vice-versa in autumn. The amplitude of the seasonal cycle of the AMOC arising from the eastern-boundary densities is $5.2 \mathrm{~Sv}$ peakto-peak, dominating the $6.7 \mathrm{~Sv}$ peak-to-peak seasonal cycle of the total AMOC. Our analysis suggests that the seasonal cycle in density may be forced by the strong near-coastal seasonal cycle in wind stress curl.

\section{Introduction}

The Atlantic Meridional Overturning Circulation (AMOC) moves northward approximately $19 \mathrm{~Sv}\left(1 \mathrm{~Sv} \equiv 10^{6} \mathrm{~m}^{3} \mathrm{~s}^{-1}\right)$ of warm, saline waters above roughly $1000 \mathrm{~m}$ depth and the same amount of cold water back south below $1000 \mathrm{~m}$. The AMOC plays a key role in the meridional heat transport in the North Atlantic and the resulting heat release to the atmosphere on the water's way towards high latitudes. In the past, the strength of the AMOC was estimated from temporally sparse hydrographic observations (e.g., Worthington, 1976; Hall and Bryden, 1982; Roemmich and Wunsch, 1985; Bryden et al., 2005; Longworth, 2007). The insufficient temporal resolution, however, would complicate the analysis of variability or the detection of trends in the AMOC. To monitor continuously the temporal evolution of the AMOC at $26.5^{\circ} \mathrm{N}$, the RAPID (Rapid Climate Change)/MOCHA (Meridional Overturning Circulation and

Published by Copernicus Publications on behalf of the European Geosciences Union. 
Heat Transport Array) array become operational in 2004 (Hirschi et al., 2003; Kanzow et al., 2008). The strength of the $\mathrm{AMOC}$ at $26.5^{\circ} \mathrm{N}$ is calculated by adding the northward transport from three contributions: the Gulf Stream transport through the Straits of Florida, measured by a submarine cable; the near surface Ekman transport, measured by satellite scatterometry; and the mid-ocean geostrophic transport across the $6000 \mathrm{~km}$ wide zonal section between the Bahamas and Africa, measured by the RAPID/MOCHA mooring array proper. Using the RAPID/MOCHA data, we here analyze the eastern-boundary contributions to sub-seasonal and seasonal AMOC variability.

Results from the first year of the RAPID/MOCHA array have demonstrated the ability of the observing system to measure the strength and vertical structure of the AMOC continuously (Kanzow et al., 2007). Cunningham et al. (2007) determined the time mean of the AMOC at $26.5^{\circ} \mathrm{N}$ between 29 March 2004 and 31 March 2005 as 18.7 Sv, with a temporal standard deviation of $\pm 5.6 \mathrm{~Sv}$. Variations of the Gulf Stream transport (of $\pm 3.3 \mathrm{~Sv}$ ), the Ekman transport (of $\pm 4.4 \mathrm{~Sv}$ ) and the upper mid-ocean geostrophic transport (of $\pm 3.1 \mathrm{~Sv}$ ) contributed about equally to the AMOC temporal variability. The impact of eastern-boundary density changes on the AMOC, however, has not been studied systematically. Usually, the western boundary currents are assumed to be primarily responsible for AMOC variability, and thus density variability at the western boundary of the North Atlantic is expected to be larger than at the eastern boundary (Johnson and Marshall 2004; Longworth, 2007). Using historical density profiles from hydrographic cruises, Longworth (2007) investigated to what extent transport fluctuations in the 0 $800 \mathrm{~m}$ layer of the mid-ocean section at $26^{\circ} \mathrm{N}$ arose from western-boundary or eastern-boundary density variability. She found that the western-boundary contribution was twice as large as the eastern-boundary contribution $( \pm 2.8 \mathrm{~Sv}$ vs. $\pm 1.5 \mathrm{~Sv} \mathrm{rms})$. However, this estimate is very uncertain since it is based on only five transatlantic CTD sections. On the other hand Kanzow et al. (2009a) found evidence that boundary wave dynamics provide an efficient mechanism to suppress eddy and Rossby wave induced density fluctuations right at the western boundary. Using the comprehensive data set now available through RAPID/MOCHA, we investigate as our first objective whether the amplitude and frequency distribution of eastern-boundary density variability is an important contribution to sub-seasonal and seasonal anomalies of the strength and vertical structure of the AMOC at $26.5^{\circ} \mathrm{N}$ between April 2004 and October 2007.

The core of RAPID/MOCHA is a hydrographic mooring array along $26.5^{\circ} \mathrm{N}$ to monitor the mid-ocean flow. Between April 2004 and October 2007 two density monitoring systems have been maintained continuously at the eastern boundary: (i) a tall $5000 \mathrm{~m}$-long offshore mooring (EB1) located at the base of the African continental slope at $23^{\circ}$ $48.6^{\prime} \mathrm{N}, 24^{\circ} 5.7^{\prime} \mathrm{W}$, and (ii) an array of short (about $500 \mathrm{~m}$ long) moorings on the slope covering different vertical levels
(EBH). It is desirable to measure density right at the boundary (as with EBH), in order to compute the transatlantic midocean geostrophic transports; however, measurements offshore of the upwelling regime (EB1) would reduce the risk of data loss due to fishing activity (Rayner et al., 2007). Therefore, we explore as our second objective whether indeed the density anomalies are coherent at EB1 and EBH such that EB1 might serve as a backup or replacement of $\mathrm{EBH}$, as was formulated in the original observing system design (Marotzke et al., 2002).

Among the mechanisms that may change densities at the eastern boundary at $26.5^{\circ} \mathrm{N}$, and thus the strength of the AMOC, are Kelvin waves propagating poleward (Kawase, 1987; Johnson and Marshall, 2002), or wind-driven changes in the strength of the Canary Current, or coastal upwelling created by anomalies in the local wind stress along the coasts (Köhl et al., 2005), or the generation of cyclonic and anticylonic eddies at the flank of the Canary Islands (HernándezGuerra et al., 1993). As our third objective in this paper, we investigate in a preliminary fashion whether our data allow us to distinguish among these mechanisms.

This paper is structured as follows. In Sect. 2 we introduce the two mooring data sets. Section 3 establishes the methodology to infer the eastern-boundary density contribution to AMOC variability. Section 4 describes the main hydrographic characteristics. Section 5 gives the analysis of the temporal evolution of the observed flows, their vertical structure, and a comparison of the transport contributions as obtained from EB1 and EBH. Section 6 details the seasonal variability of the density fluctuations at the eastern boundary of the subtropical North Atlantic off Morocco. Section 7 provides a discussion, and Sect. 8 presents our conclusions.

\section{Data}

The RAPID/MOCHA array was first deployed in spring 2004 , and has been operating continuously since then. Kanzow et al. (2008) gave a detailed description of the full array (see also www.noc.soton.ac.uk/rapidmoc). The northward flow of warm water through the $800 \mathrm{~m}$ deep Straits of Florida is monitored by a submerged telephone cable crossing the Straits between Florida and the Bahamas (Larsen, 1992; Baringer and Larsen, 2001). The Ekman transport is derived from QuikSCAT satellite scatterometry (Kanzow et al., 2007). The currents over the steep western boundary continental slope are obtained by direct velocity measurements (Johns et al., 2008). The mid-ocean flow is monitored by a hydrographic mooring array along the $26.5^{\circ} \mathrm{N}$ section between the Bahamas at about $77^{\circ} \mathrm{W}$ and the African Coast at about $15^{\circ} \mathrm{W}$. The transatlantic array consists of the westernboundary (east of the Bahamas), the mid-Atlantic Ridge, and the eastern-boundary (west of Morocco) sub-arrays (Fig. 1). The full-depth moorings have between 11 and 24 CTD sensors at fixed depths throughout the water column. Some 


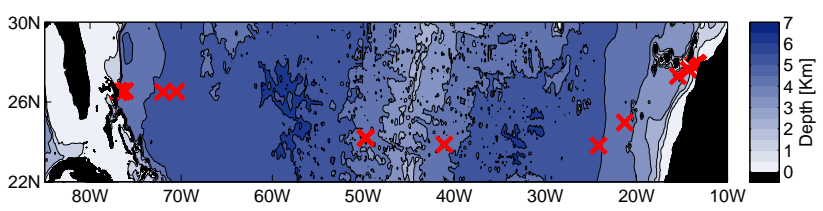

Fig. 1. Distribution of the RAPID/MOCHA moorings across $26.5^{\circ} \mathrm{N}$ as deployed for year 2007 .

of the moorings of the western-boundary sub-array (WB0, WB3, WB5) (Johns et al., 2008; their Fig. 1) are serviced at 18 -months intervals; the remaining moorings of the full array are serviced at annual intervals (during autumn for the eastern boundary). The western-boundary and eastern-boundary moorings constitute the endpoint density profiles required to calculate the basin-wide zonally integrated geostrophic flow.

\subsection{The eastern-boundary sub-array}

The eastern-boundary sub-array as deployed for the year 2007 is shown in Fig. 2; the nominal positions and water depths of the moorings are given in Table 1. The full water-column mooring EB1 is situated at the base of the continental slope, roughly $1250 \mathrm{~km}$ from the coast. On the first year (2004) EB1 was deployed at a nominal position of $24^{\circ} 31.4^{\prime} \mathrm{N}, 23^{\circ} 26.9^{\prime} \mathrm{W}$. From the second year (2005) onwards, EB1 was moved to a nominal position of $23^{\circ} 48.6^{\prime} \mathrm{N}$, $24^{\circ} 5.7^{\prime} \mathrm{W}$ with the purpose of locating it on a satellite track. The inshore array (EBH) consists of a series of shorter moorings distributed between the African shelf and the base of the eastern continental slope. Each of these "small" moorings covers a certain depth range such that all of them merged together account for the full boundary density profile between the surface and $5000 \mathrm{~m}$.

The periods of the mooring records and the nominal depths of the CTD sensors are given in Tables 2 and 3 for EB 1 and EBH, respectively. Vertical sensor spacing increases with depth from roughly $100 \mathrm{~m}$ near the sea surface, to $200 \mathrm{~m}$ at the bottom of the thermocline, to $500 \mathrm{~m}$ in the deep ocean. During the different deployment periods the array has been subject to some minor design changes. Initially, from March 2004 to April 2005, EB1 occupied the depth range between 2500 dbar and 4850 dbar. Since April 2005 EB1 has covered the entire water column, with 24 sensors ( 21 sensors between November 2005 and May 2006). The re-deployment of EB1 failed in October 2006, and it was only re-deployed during a cruise in December 2006. For this reason, there is a time gap of ca. 2 months (from 8 October 2006 to 1 December 2006, Table 2). Each of the moorings of the EBH array has between 1 and 6 CTD sensors. In order to obtain the eastern-boundary profile for the first deployment period (March 2004 to April 2005), the measurements at EBH5, $\mathrm{EBH} 4, \mathrm{EBH} 3, \mathrm{EBH} 2, \mathrm{EBH} 1$ and $\mathrm{EB} 1$ are merged into one profile. In this way, EBH5 provides the density profile be-
Table 1. Nominal positions and water depths of eastern-boundary moorings. Note that the position of EB1 changed slightly between the first year's deployment (2004) and the subsequent deployments (2005 onwards). The position of EB1 corresponds to year 2005 deployment, while the position corresponding to the year 2004 is given in brackets.

\begin{tabular}{lccc}
\hline $\begin{array}{l}\text { Mooring } \\
\text { name }\end{array}$ & $\begin{array}{c}\text { Latitude } \\
\text { (North) }\end{array}$ & $\begin{array}{c}\text { Longitude } \\
\text { (West) }\end{array}$ & $\begin{array}{c}\text { Water Depth } \\
{[\mathrm{m}]}\end{array}$ \\
\hline EB1 & $23^{\circ} 48.6^{\prime}\left(24^{\circ} 31.4^{\prime}\right)$ & $24^{\circ} 5.7^{\prime}\left(23^{\circ} 26.9^{\prime}\right)$ & 5000 \\
EBH1 & $27^{\circ} 16.5^{\prime}$ & $15^{\circ} 25.0^{\prime}$ & 3012 \\
EBH2 & $27^{\circ} 29.2^{\prime}$ & $14^{\circ} 41.0^{\prime}$ & 2510 \\
EBH3 & $27^{\circ} 37.3^{\prime}$ & $14^{\circ} 12.3^{\prime}$ & 2005 \\
EBH4 & $27^{\circ} 49.9^{\prime}$ & $13^{\circ} 47.3^{\prime}$ & 1510 \\
EBH5 & $27^{\circ} 51.4^{\prime}$ & $13^{\circ} 31.2^{\prime}$ & 1015 \\
EBHi & $24^{\circ} 57.3^{\prime}$ & $21^{\circ} 15.4^{\prime}$ & 4499 \\
EBH0 & $26^{\circ} 59.6^{\prime}$ & $16^{\circ} 13.7^{\prime}$ & 3511 \\
EBM1 & $27^{\circ} 53.6^{\prime}$ & $13^{\circ} 24.4^{\prime}$ & 500 \\
EBM2 & $27^{\circ} 54.0^{\prime}$ & $13^{\circ} 23.4^{\prime}$ & 400 \\
EBM3 & $27^{\circ} 54.3^{\prime}$ & $13^{\circ} 22.3^{\prime}$ & 325 \\
EBM4 & $27^{\circ} 54.5^{\prime}$ & $13^{\circ} 21.9^{\prime}$ & 250 \\
EBM5 & $27^{\circ} 54.6^{\prime}$ & $13^{\circ} 21.5^{\prime}$ & 175 \\
EBM6 & $27^{\circ} 55.2^{\prime}$ & $13^{\circ} 19.9^{\prime}$ & 100 \\
EBM7 & $27^{\circ} 54.4^{\prime}$ & $13^{\circ} 13.5^{\prime}$ & 50 \\
\hline
\end{tabular}

a)

b)
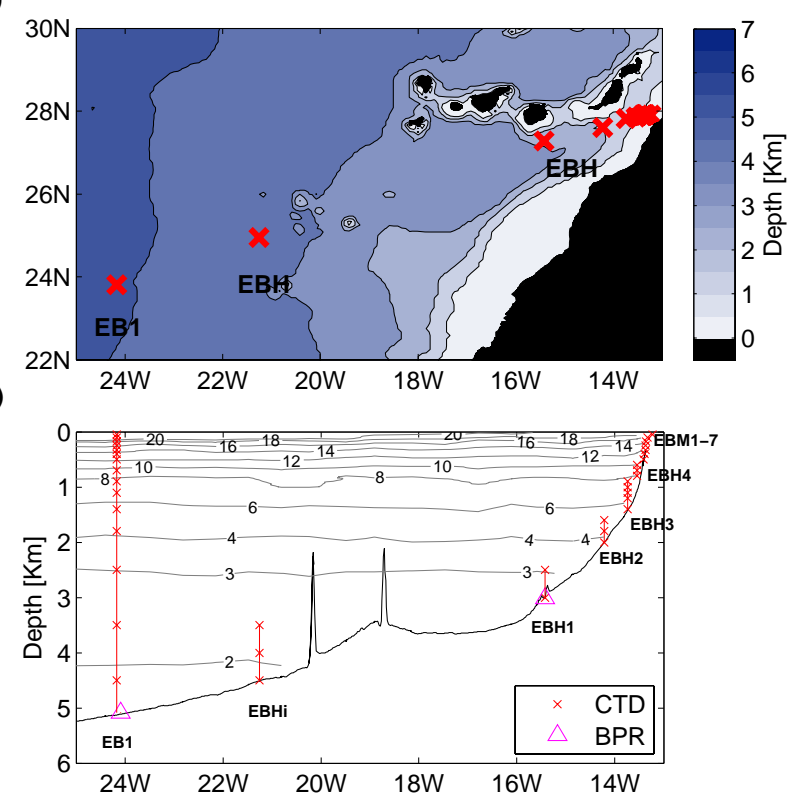

Fig. 2. (a) Location of the moorings near the eastern boundary of the $26.5^{\circ} \mathrm{N}$ section (red crosses), (b) distribution of CTD sensors and bottom pressure recorders (BPR) at the eastern boundary array as deployed for year 2007. The contours represent potential temperature in ${ }^{\circ} \mathrm{C}$ from a CTD transatlantic section at a nominal latitude of $24.5^{\circ} \mathrm{N}$ carried out in year 2004 .

tween $565 \mathrm{dbar}$ and $965 \mathrm{dbar}$, EBH4 between $1060 \mathrm{dbar}$ to $1460 \mathrm{dbar}$, EBH3 between $1555 \mathrm{dbar}$ and $1955 \mathrm{dbar}$, EBH2 at $2060 \mathrm{dbar}$ and EBH1 between $2562 \mathrm{dbar}$ and $2762 \mathrm{dbar}$. Deep eastern-boundary measurements are taken from EB1 
Table 2. Periods of mooring records and nominal pressure levels of sensors of EB1 mooring.

\begin{tabular}{|c|c|c|c|}
\hline Start Date & End Date & Nominal Instrument Pressures [dbar] & T/S Levels \\
\hline 4-Mar-04 & 7-Apr-05 & $2500,3000,3500,4000,4500,4850$ & 6 \\
\hline 13-Apr-05 & 18-Nov-05 & $\begin{array}{l}94,144,219,294,369,444,544,644,744,844,944,1044,1144,1244, \\
1444,1644,1844,2044,2544,3044,3544,4044,4544,4894\end{array}$ & 24 \\
\hline 28-Nov-05 & 3-May-06 & $\begin{array}{l}250,325,400,500,600,700,800,900,1000,1100,1200,1400,1600, \\
1800,2000,2500,3000,3500,4000,4500,4850\end{array}$ & 21 \\
\hline 22-May-06 & 8-Oct-06 & $\begin{array}{l}110,160,250,325,400,475,550,650,750,850,950,1050,1150, \\
1250,1450,1550,1750,1950,2150,2650,3150,3650,4150,4800\end{array}$ & 24 \\
\hline 1-Dec-06 & 14-Oct-07 & $\begin{array}{l}50,100,175,250,325,400,500,600,700,800,900,1000,1100,1200, \\
1400,1600,1800,2000,2500,3000,3500,4000,4500,4850\end{array}$ & 24 \\
\hline
\end{tabular}

Table 3. Periods of mooring records and nominal pressure levels of sensors of EBH array.

\begin{tabular}{|c|c|c|c|}
\hline Start Date & End Date & Nominal Instrument Pressures [dbar] & T/S Levels \\
\hline 4-Mar-04 & 1-Apr-05 & $\begin{array}{l}565,665,765,915,965 \text { (ЕBH5); 1060, 1160, 1260, 1410, } 1460 \text { (ЕBH4); 1555, } \\
1655,1755,1905,1955 \text { (ЕВH3); } 2060 \text { (ЕBH2); 2562, } 2762 \text { (ЕВH1) }\end{array}$ & 18 \\
\hline 13-Apr-05 & 2-Feb-06 & $\begin{array}{l}\text { 50, 100, 175, } 250(\mathrm{EBH} 5)^{* *} ; 240,315,415,515,615,715,815(\mathrm{EBH} 4)^{*} ; 911, \\
1011,1111,1211,1411(\mathrm{EBH} 3)^{* *} ; 1600,1800,1990(\mathrm{EBH} 2)^{* *} ; 2510,2990 \\
(\mathrm{EBH} 1)^{* *} ; 3490(\mathrm{EBH}) ; 3510,4010,4490(\mathrm{EBHi})^{* *}\end{array}$ & 24 \\
\hline 22-May-06 & 4-Oct-06 & $\begin{array}{l}50,100,175,250 \text { (EBH5); 325, 400, 500, 600, 700, } 800 \text { (EBH4); 900, 1000, } \\
1100,1200,1400 \text { (EBH3); 1600, 1800, } 2000(\mathrm{EBH} 2) ; 2500,3000 \text { (EBH1); } \\
3500 \text { (EBH0); } 4000 \text { (EBHi) }\end{array}$ & 22 \\
\hline 12-Oct-06 & 14-Oct-07 & $\begin{array}{l}50(\mathrm{EBM} 7)^{*} ; 100 \text { (EBM6)*; } 174(\mathrm{EBM} 5)^{*} ; 253 \text { (EBM4); } 325(\mathrm{EBM} 3)^{*} ; 400 \\
(\mathrm{EBM}) * ; 515 \text { (EBM1); 600, 700, } 800 \text { (EBH4); 900, 1000, 1100, 1200, } 1400 \\
(\mathrm{EBH} 3) ; 1600,1800,2000 \text { (EBH2); 2500, } 3000 \text { (EBH1); } 3500 \text { (EBH0); 3500, } \\
\text { 4000, } 4500 \text { (EBHi) }\end{array}$ & 23 \\
\hline
\end{tabular}

${ }^{*}$ not recovered; ${ }^{* *}$ battery failures.

(below roughly $3000 \mathrm{dbar}$ ). The same merging procedure applies to the following years. From April 2005, the EBH array had consistently measurements above $500 \mathrm{dbar}$ and two additional moorings (EBH0 and EBHi) were deployed across the slope to account for density measurements in the 3500 4500 dbar pressure range. During the second deployment period, all the sensors stopped recording due to battery failures, producing a gap in the data of ca. 3 months (from 2 February 2006 to 22 May 2006, Table 3).

The data recovery on the slope was complicated by mooring losses, most likely due to fisheries activities south of the Canary Islands. For instance, for the period from April 2005 to February 2006, one of the shallower moorings (EBH4) could not be recovered leading to a data loss at the 300$800 \mathrm{dbar}$ pressure range (Rayner et al., 2007). In an at- tempt to reduce the potential impact of fishing activity, in the deployment during October 2006 the shallowest mooring EBH5 was divided into a set of smaller "mini-moorings", EBM1 to EBM7, consisting of only one CTD sensor per mooring. However, only two of the "mini-moorings" returned data (EBM4 and EBM1, at 253 dbar and 515 dbar respectively), two more were recovered with sensors missing (EBM5 and EBM6).

\subsection{Data acquisition and processing}

All the moored sensors discussed here are Seabird SBE37 (MicroCAT), which measure temperature, conductivity and pressure. The sensors acquire data at sampling rates between 15 and $30 \mathrm{~min}$. For calibration, all moored CTD sensors are 
lowered on a frame together with a reference CTD package (SBE 911) before and after each deployment period. Calibration coefficients for each sensor are computed and linear trends are removed following Kanzow et al. (2006). An overall accuracy of $0.001{ }^{\circ} \mathrm{C}, 0.002 \mathrm{mS} / \mathrm{cm}$ and $1 \mathrm{dbar}$ relative to the reference CTD is achieved.

Using all the information described in Sect. 2.1, full-depth continuous profiles of temperature and salinity and thus of density $(\rho)$ are obtained at each site as follows. Salinity is computed and temperature, salinity, and pressure are two-day low-pass filtered and interpolated on a half-daily grid. Temperature and salinity are vertically interpolated onto a regular 20-dbar pressure grid (Kanzow et al., 2007) using an interpolation technique relying on climatological temperature and salinity gradients between vertically adjacent sensor levels (Johns et al., 2005). Each MicroCAT has a pressure sensor so that when interpolating the temperature and salinity profiles between adjacent pressure levels of measurements on a regular pressure grid, the measured pressures at each time step are taken into account to avoid mooring motion effects. Finally $\rho$ is computed. For each deployment period, upward integration of temperature and salinity is done up to the uppermost level of measurements available. The only exceptions are for year 2004 and year 2007 at EBH, when the uppermost level of measurements was $540 \mathrm{dbar}$ and $240 \mathrm{dbar}$, respectively, and the data were extrapolated to $120 \mathrm{dbar}$ at each time step as follows. For the year 2004 temperature and salinity are linearly extrapolated to $240 \mathrm{dbar}$ by estimating the gradient from the anomalies at 840 and 540 dbars and then carrying the anomaly at $240 \mathrm{dbar}$ at constant value up to 120 dbar (Kanzow et al., 2007, Supporting Online Material). For the year 2007, the data are linearly extrapolated to $120 \mathrm{dbar}$ on the basis of the gradient of the anomaly between the two uppermost levels of measurements.

\section{Transport calculations}

We start by describing briefly how a time series of strength of the AMOC, $\psi_{\operatorname{MAX}}(t)$, is computed from the observational data (for more details see Kanzow et al., 2009b). Then we show how the contribution of eastern-boundary density variations to the AMOC is calculated.

At $26.5^{\circ} \mathrm{N}, \psi_{\operatorname{MAX}}(t)$ is calculated by the sum of three meridional flow components: the northward Gulf Stream transport through the Straits of Florida $\left(T_{\mathrm{GS}}\right)$, the zonally integrated near-surface Ekman transport $\left(T_{\mathrm{EK}}\right)$, and the geostrophic mid-ocean transport between the Bahamas and the African coast $\left(T_{\mathrm{MO}}\right)$. From these transport contributions, a vertical profile of zonally integrated northward transport per unit depth $\left(T_{\mathrm{AMOC}}\right)$ is computed such that

$T_{\mathrm{AMOC}}(z, t)=T_{\mathrm{GS}}(z, t)+T_{\mathrm{EK}}(z, t)+T_{\mathrm{MO}}(z, t)$,

where $z$ denotes depth. $\psi_{\text {MAX }}(t)$ at $26.5^{\circ} \mathrm{N}$ is defined at each time step as the maximum northward transport in the upper ocean. The northward transport is integrated downward from the sea surface to the depth level $h_{\max }(t)$ where the maximum cumulative northward transport is reached at each time step (that is, the depth where the zero crossing between northward and southward flow occurs), according to

$$
\Psi_{\mathrm{MAX}}(t)=\int_{z=-h \max }^{z=0} T_{\mathrm{AMOC}}(z, t) d z .
$$

For the computation of $T_{\mathrm{AMOC}}(z, t), T_{\mathrm{GS}}(z, t)$ and $T_{\mathrm{EK}}(z, t)$ are computed directly from the cable and wind observations respectively. The cable measurements give an estimate of the vertically integrated transport $T_{\mathrm{GS}}(t)$. The modal vertical structure of the flow through the Straits of Florida is estimated from historical Pegasus measurements across the straits. Subsequently, the vertical structure $T_{\mathrm{GS}}(z, t)$ is obtained by projecting $T_{\mathrm{GS}}$ onto the leading vertical mode of the meridional transport per unit depth, which accounts for $87 \%$ of the variance (Baringer et al., 2008). $T_{\mathrm{EK}}(t)$ is computed by zonally integrating the Ekman transport between the shelf of Abaco (Bahamas) $\left(X_{\mathrm{A}}\right)$ and the African coast $\left(X_{\mathrm{E}}\right)$ following

$T_{\mathrm{EK}}(t)=-\int_{X_{\mathrm{A}}}^{X_{\mathrm{E}}} \frac{\tau_{x}(x, t)}{\rho f} d x$

where $\tau_{x}$ is the zonal component of the wind stress, $\rho$ is a reference density and $f$ is the Coriolis parameter. In order to obtain vertical transport per unit depth profiles $T_{\mathrm{EK}}(z, t)$ that are consistent with previous studies, the transports in $T_{\mathrm{EK}}$ are equally distributed in the upper $100 \mathrm{~m}$ (Kanzow et al., 2007; Cunningham et al., 2007).

$T_{\mathrm{MO}}(z, t)$ has two components: the transport $T_{\mathrm{WBW}}(z, t)$ through the western boundary wedge over the Bahamas continental slope - calculated from direct current meter measurements (Johns et al., 2008) - and the geostrophic transport between the Bahamas and the African coast. The latter is computed from the internal transport, $T_{\mathrm{INT}}$, calculated from the east to west density gradient and a reference transport $T_{\mathrm{C}}$. $T_{\text {INT }}$ is computed by means of the vertical density profiles at the western boundary and the eastern boundary $\left(\rho_{\mathrm{W}}\right.$ and $\left.\rho_{\mathrm{E}}\right)$, relative to a reference level $\left(h_{\text {ref }}\right)$, according to

$$
\begin{aligned}
& T_{\mathrm{INT}}(z, t)=-(g / \rho f) \int_{z^{\prime}=-h_{\mathrm{ref}}}^{z}\left[\rho_{\mathrm{E}}\left(z^{\prime}, t\right)-\rho_{\mathrm{W}}\left(z^{\prime}, t\right)\right] d z^{\prime}, \\
& \text { for } z>-h_{\mathrm{ref}},
\end{aligned}
$$

where $g$ is the Earth's gravitational acceleration, $\rho$ is a reference density, and $f$ is the Coriolis parameter. To compute absolute values of $T_{\mathrm{MO}}(z, t)$, a reference transport for $T_{\mathrm{INT}}(z, t)$ needs to be computed at each time step. This is 
calculated by the imposition of no net mass transport across the longitude-depth section at $26.5^{\circ} \mathrm{N}$, which is justified for timescales longer than 10 days (Kanzow et al., 2007). This constraint is equivalent to a perfect compensation among the different flow components, according to

$\int_{z=-h_{\mathrm{bot}}}^{z=0}\left[T_{\mathrm{GS}}(z, t)+T_{\mathrm{EK}}(z, t)+T_{\mathrm{MO}}(z, t)\right] d z=0$,

where $h_{\text {bot }}$ represents the depth of the sea floor.

The reference transport of $T_{\mathrm{INT}}(z, t)$, namely $T_{\mathrm{C}}(\mathrm{t})$, is computed at each time step according to

$$
\begin{aligned}
& T_{\mathrm{C}}(t)=-\int_{z=-h_{\mathrm{bot}}}^{z=0}\left[T_{\mathrm{GS}}(z, t)+T_{\mathrm{EK}}(z, t)+T_{\mathrm{WBW}}(z, t)\right. \\
& \left.+T_{\mathrm{INT}}(z, t)\right] d z .
\end{aligned}
$$

The computation of $T_{\mathrm{C}}$ is performed assuming that the compensating meridional velocity field $V_{\mathrm{C}}(x, z)$ is spatially uniform (Hirschi et al., 2003) such that

$$
T_{\mathrm{C}}=V_{\mathrm{C}} \int_{z=-h_{\text {bot }}}^{z=0} \int_{X_{\mathrm{E}}}^{X_{\mathrm{W}}} d x d z=V_{\mathrm{C}} \int_{z=-h_{\text {bot }}}^{z=0} L(z) d z,
$$

where $X_{\mathrm{W}}$ and $X_{\mathrm{E}}$ denote the position of the western and eastern boundary endpoints, and $L$ is the effective width of the transatlantic section, which reduces with depth (Kanzow et al., 2009b).

The absolute mid-ocean transport is then given by

$T_{\mathrm{MO}}(z, t)=T_{\mathrm{WBW}}(z, t)+T_{\mathrm{INT}}(z, t)+T_{\mathrm{C}}(z, t)$,

with $T_{\mathrm{C}}(z, t)=V_{\mathrm{C}} L(z)$.

How then is the transport contribution of eastern-boundary densities to $\psi_{\operatorname{MAX}}(t)$ isolated? The basic concept is to perform the transport calculations such that the only timevariable contribution comes from eastern-boundary densities. As there is no significant correlation between density fluctuations at the western boundary (off the Bahamas) and the eastern boundary for annual and higher frequencies (Kanzow et al., 2009b), we can isolate the eastern-boundary contribution to $T_{\mathrm{MO}}(z, t)$ by prescribing a time-invariant density profile at the western boundary at each time step in Eq. (4). We use

$$
\begin{aligned}
& T_{\mathrm{INT}}^{\mathrm{EB}}(z, t)=-(g / \rho f) \int_{z^{\prime}=-h_{\mathrm{ref}}}^{z}\left[\rho_{\mathrm{E}}\left(z^{\prime}, t\right)-\bar{\rho}_{\mathrm{W}}\left(z^{\prime}\right)\right] d z^{\prime}, \\
& \text { for }-h_{\mathrm{ref}}<z<-h_{\mathrm{up}},
\end{aligned}
$$

where the overbar denotes the time-average. The reference depth, $h_{\text {ref }}$, is taken as the greatest common depth of the moorings in the east (4900 m), and $h_{\text {up }}$ represents the uppermost measurement level at the eastern boundary; $h_{\text {up }}$ differs between the different mooring deployment periods (Tables 2 and 3). To obtain estimates for the entire water column, the profiles of transport per unit depth resulting from Eq. (9) are linearly extrapolated from the uppermost measurement level to the surface for each time step, on the basis of the gradient of the transport anomaly between the two uppermost levels of measurements. When required, the profiles are linearly interpolated in time to fill the time gaps of 1-2 weeks between mooring recovery and redeployment.

We then add at each time step the resulting transport per unit depth anomaly profiles arising from Eq. (9) to the timemean contribution of all the other components according to

$$
\begin{aligned}
& T_{\mathrm{AMOC}}^{\mathrm{EB}}(z, t)=\bar{T}_{\mathrm{GS}}(z)+\bar{T}_{\mathrm{EK}}(z)+\bar{T}_{\mathrm{WBW}}(z)+T_{\mathrm{INT}}^{\mathrm{EB}}(z, t) \\
& \quad+T_{\mathrm{C}}^{\mathrm{EB}},
\end{aligned}
$$

such that the compensating transport at each time step $T_{\mathrm{C}}^{\mathrm{EB}}(t)$ is given by

$$
\begin{aligned}
& T_{\mathrm{C}}^{\mathrm{EB}}(t)=-\int_{z=-h_{\mathrm{bot}}}^{z=0}\left[\bar{T}_{\mathrm{GS}}(z)+\bar{T}_{\mathrm{EK}}(z)+\bar{T}_{\mathrm{WBW}}(z)\right. \\
& \left.+T_{\mathrm{INT}}^{\mathrm{EB}}(z, t)\right] d z .
\end{aligned}
$$

Consistent with Eq. (2), the eastern-boundary density contribution to the strength of the AMOC is computed from

$$
\Psi_{\mathrm{MAX}}^{\mathrm{EB}}(t)=\int_{z=-h \text { max _eb }}^{z=0} T_{\mathrm{AMOC}}^{\mathrm{EB}}(z, t) d z,
$$

where $h_{\max \_\mathrm{eb}}(t)$ is the depth where the zero crossing between northward and southward flow occurs at each time step for $T_{\mathrm{AMOC}}^{\mathrm{EB}}(z, t)$.

As motivated in Sect. 1, $\Psi_{\mathrm{MAX}}^{\mathrm{EB}}(t)$ is computed using the densities observed at either EB1 or EBH. The profiles of transport per unit depth computed according to Eq. (10) using EB1 and EBH will be referred to as $T_{\mathrm{AMOC}}^{\mathrm{EB} 1}$ and $T_{\mathrm{AMOC}}^{\mathrm{EBH}}$, respectively. The eastern-boundary density contributions to the AMOC computed from Eq. (12) will be referred to as $\Psi_{\mathrm{MAX}}^{\mathrm{EB} 1}$ and $\Psi_{\mathrm{MAX}}^{\mathrm{EBH}}$, respectively.

\section{Eastern-boundary hydrographic characteristics}

Next we examine the hydrographic properties of the water masses observed at EB1 and EBH to explore whether the temporal fluctuations of the properties between the two sites are coherent. For this, we examine temporal anomalies. Both data sets cover the period from 4 March 2004 to 14 October 2007 (ca. 3.5 years of data). Notice that for clearer visualization, we plot and discuss temporal anomalies relative to the time mean of each separate deployment period (Figs. 3, 4,5 and 6). In all calculations based on density anomalies, however, we compute temporal anomalies relative to the time 


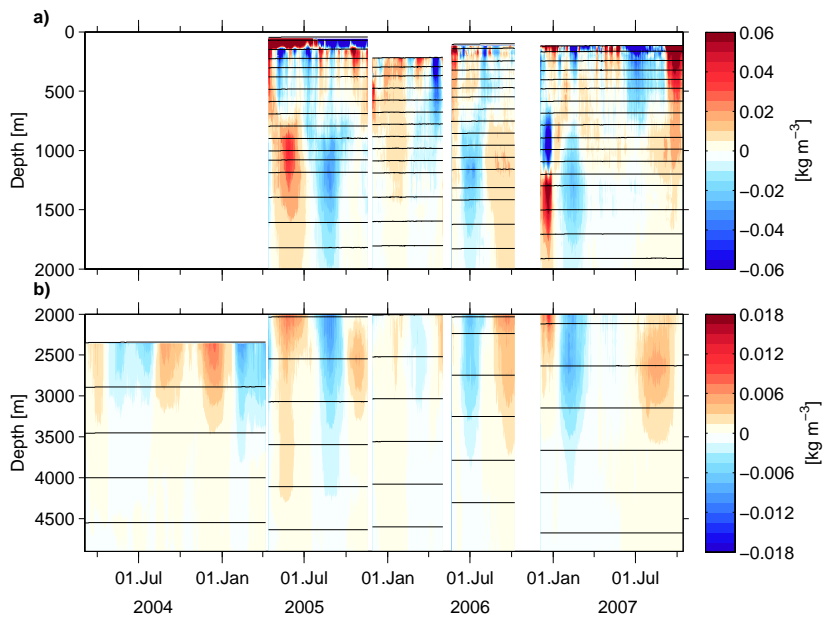

Fig. 3. 2-day low-pass filtered in-situ density anomaly at EB1, (a) from 0 to $2000 \mathrm{~m}$ and (b) from $2000 \mathrm{~m}$ to the bottom. Dates go from 4 March 2004 to 14 October 2007. For clarity, the anomalies computed around the time mean for each deployment period are shown. Note that panels (a) and (b) have different color scales. Horizontal lines are the levels of the measurements.

mean of the entire 3.5 years unless explicitly noted. Throughout this study fluctuations are reported in \pm one standard deviation.

The density at EB1 shows the strongest anomalies near the surface (Fig. 3a); these near-surface anomalies are mainly associated with temperature fluctuations (Fig. 4a). This is most evident during the period from April 2005 to November 2005, when measurements are available as shallow as $120 \mathrm{~m}$ below the surface. Away from the surface, the major density and temperature anomalies are of uniform sign between the bottom and at least ca. $800 \mathrm{~m}$, with the exception of the event in December 2006 (see below, Figs. 3 and 4). Maximum mid-depth density anomalies are found near $1000 \mathrm{~m}$ over the whole period; we observe the most intense density anomalies during May 2005, August 2005, July 2006, December 2006, and February 2007. The positive density anomaly event with a maximum by the end of May 2005 at $1000 \mathrm{~m}$ lasts for 10 weeks, with the more intense anomalies (exceeding $0.02 \mathrm{~kg} / \mathrm{m}^{3}$ ) confined to a layer between 800 and $1500 \mathrm{~m}$. This density event is associated with positive temperature and salinity anomalies of up to $0.35^{\circ} \mathrm{C}$ and 0.1 , respectively, but the latter have their maximum at ca. $800 \mathrm{~m}$, while at the depth of the maximum density anomaly (ca. $1000 \mathrm{~m}$ ) temperature and salinity anomalies of only $-0.1{ }^{\circ} \mathrm{C}$ and 0.03 are found. This implies that salinity dominates this density excursion near its maximum. There are three major events of anomalously negative density, all with similar characteristics, taking their extreme values at the end of August 2005 , at the beginning of July 2006, and at mid-February 2007, respectively, and lasting for 5-6 weeks, 3 weeks, and 5 weeks, respectively. Negative density anomalies during the

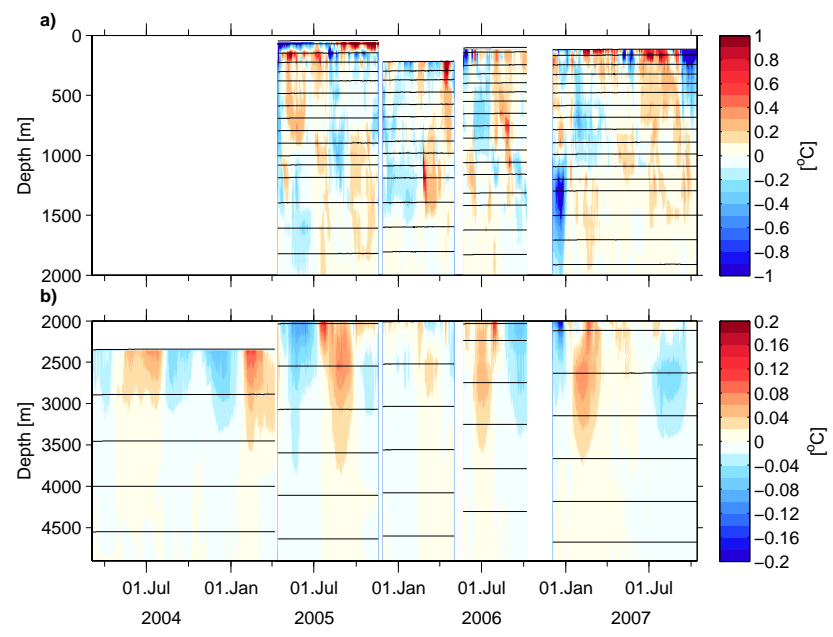

Fig. 4. 2-day low-pass filtered temperature anomaly at EB1, (a) from 0 to $2000 \mathrm{~m}$ and (b) from $2000 \mathrm{~m}$ to the bottom. Dates go from 4 March 2004 to 14 October 2007. For clarity, the anomalies computed around the time mean for each deployment period are shown. Note that panels (a) and (b) have different color scales. Horizontal lines are the levels of the measurements.

three events exceed $0.02 \mathrm{~kg} / \mathrm{m}^{3}$ at the depth interval between ca. 900 and $1500 \mathrm{~m}$. During the August 2005 and July 2006 events, density minima occur at a deeper level than the corresponding salinity and temperature extrema. During December 2006, quite a different density anomaly can be identified, with two cores of opposite sign, negative in the range 600$1200 \mathrm{~m}$ and positive in the range $1200-2000 \mathrm{~m}$. This event lasts for ca. 3 weeks, and the strongest anomalies are found at the end of December 2006, with temperature dominating the density anomaly (Figs. 3a and 4a).

Some of these features seem to be water mass anomalies associated with local small-scale eddy circulations, rather than just temperature/salinity variations due to heave of density surfaces. When the cores of the temperature and salinity anomalies offset from the density anomalies, these usually occur near the "zero" of the density anomaly. This suggests that these are lenses (the isopycnals are expanded locally, meaning anticyclonic circulation) or anti-lenses (the isopycnals are compressed locally, meaning cyclonic circulation) passing by the mooring. For instance, for the positive density event on May 2005 described above (Fig. 3a), we observe that the core of the temperature (Fig. 4a) and salinity (not shown) anomalies (ca. $800 \mathrm{~m}$ ) offset from the core of the density anomaly (ca. $1000 \mathrm{~m}$ ) (Fig. 3a), suggesting that this is a salty anti-lens passing by the mooring.

Along the EBH array, the strongest density anomalies (exceeding $\pm 0.1 \mathrm{~kg} / \mathrm{m}^{3}$ ) are found in the upper $500 \mathrm{~m}$ (Fig. 5a), occasionally extending further down in the water column to up to $1400 \mathrm{~m}$. Above $500 \mathrm{~m}$, positive density anomalies that are persistent over longer periods (3-7 weeks) occur during April-May 2004, April-May 2005 and May 2007, while 


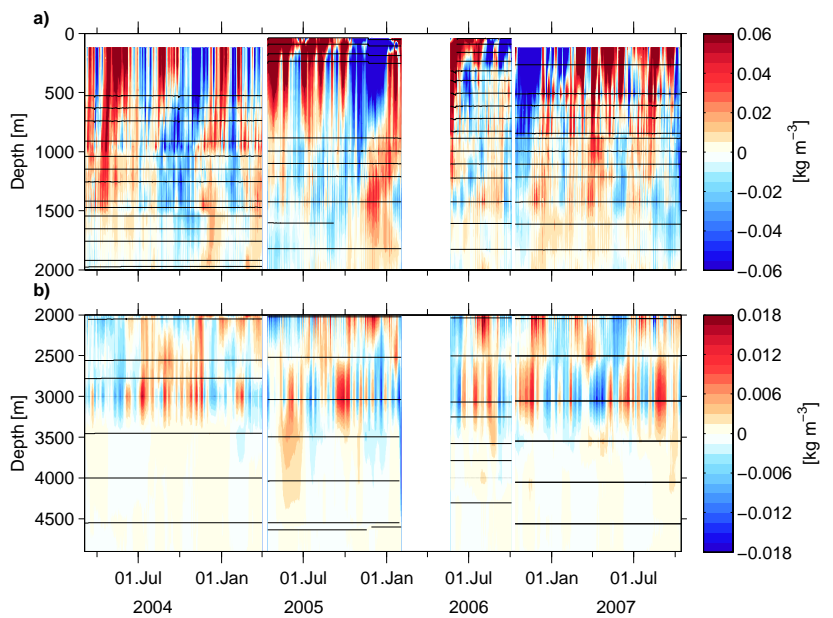

Fig. 5. 2-day low-pass filtered in-situ density anomaly at EBH, (a) from 0 to $2000 \mathrm{~m}$ and (b) from $2000 \mathrm{~m}$ to the bottom. Dates go from 4 March 2004 to 14 October 2007. For clarity, the anomalies computed around the time mean for each deployment period are shown. Note that panels (a) and (b) have different color scales. Horizontal lines are the levels of the measurements.

negative density anomalies that are persistent over longer periods (5-7 weeks) occur during October-November 2004, November-December 2005 and October-November 2006. The density anomalies in the upper ocean are dominated by temperature changes (Fig. 6a). In December 2005, pronounced mid-depth maximum positive density anomalies of $0.04 \mathrm{~kg} / \mathrm{m}^{3}$ are found at $1300 \mathrm{~m}$ (Fig. 5a); they are associated with pronounced temperature and salinity anomalies of respectively $0.7^{\circ} \mathrm{C}$ and 0.2 at the same depth level (Fig. 6a). The anomalous warm salty water occurs at depths that are expected for mixing with Mediterranean water coming out of the Strait of Gibraltar at $36^{\circ} \mathrm{N}$.

The vertical scales of the in-situ density anomalies at EB1 and EBH show pronounced differences (Figs. 3 and 5). At EB1, density anomalies extend much deeper, throughout almost the entire water column, while at EBH the density anomalies are stronger than at EB1 but they mainly occur in the upper $1400 \mathrm{~m}$. The time scales of the anomalies are also different between EB1 and EBH. At EB1 the variability is dominated by long periods of a several weeks to several months, while at EBH density anomalies exhibit pronounced short-periodic variability with dominant periods around 13 days, superimposed on longer-periodic fluctuations. A subset of the density anomalies at EBH (from November 2006 to October 2007) computed around the 3.5 year mean and bandpass filtered for the period 10-30 days, demonstrates that the 13-day oscillations are coherent down to $3500 \mathrm{~m}$ (Fig. 7). Insufficient regularity of these features rules out fortnightly tidal forcing, and so their origin is unclear at present. This large vertical coherence gives us confidence in the sampling strategy at EBH, confirming that the variability is well cap-

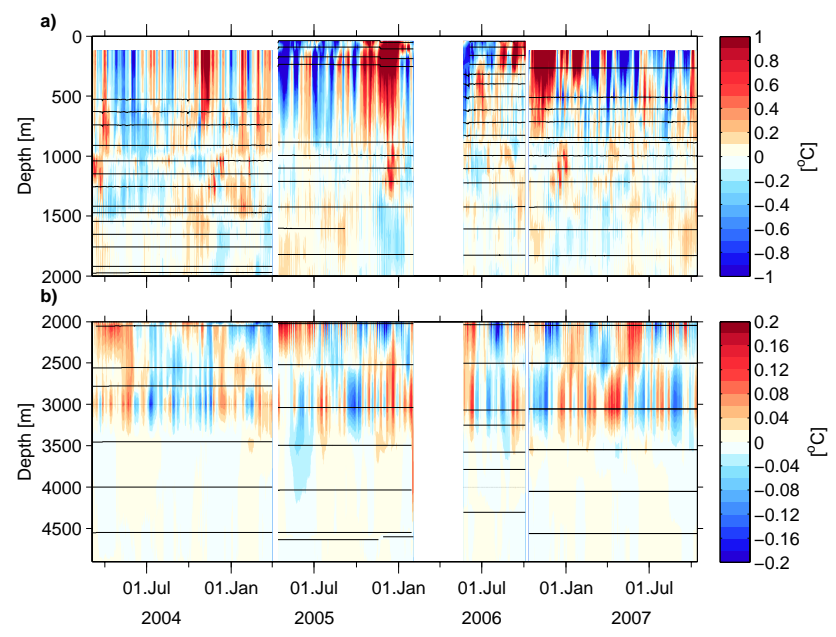

Fig. 6. 2-day low-pass filtered temperature anomaly at EBH, (a) from 0 to $2000 \mathrm{~m}$ and (b) from $2000 \mathrm{~m}$ to the bottom. Dates go from 4 March 2004 to 14 October 2007. For clarity, the anomalies computed around the time mean for each deployment period are shown. Note that panels (a) and (b) have different color scales. Horizontal lines are the levels of the measurements.

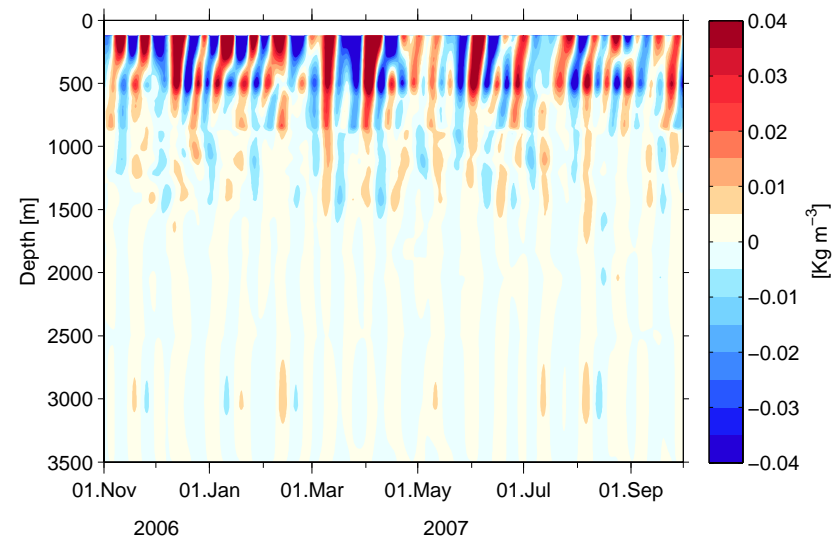

Fig. 7. 10-30 day band-pass filtered in-situ density anomalies at EBH. Dates go from 1 November 2006 to 30 September 2007, because for better visualization only a subset of the 42-month long data set is displayed.

tured by the "merging" of the moorings distributed across the continental slope.

The temporal standard deviations of temperature, salinity and in-situ density at EB1 and EBH computed for the period between 13 April 2005 and 14 October 2007 (when both moorings have full-depth measurements) are shown in Fig. 8. Both EB1 and EBH display the most pronounced differences in rms variability in temperature, salinity and density between $220 \mathrm{~m}$ and $800 \mathrm{~m}$ (Fig. 8, Table 4). Amplitudes at EB1 are smaller than those at EBH above $800 \mathrm{~m}$. At both sites, the largest variability is found in the uppermost level of measurements (220 m at EB1 and $120 \mathrm{~m}$ at EBH). 
Table 4. Time mean and standard deviation at selected depth levels between the surface and $2500 \mathrm{~m}$ of temperature $(T)$, salinity $(S)$, and insitu density $(\rho)$ at EB1 and EBH. The time mean and standard deviation is computed for the period when both EB1 and EBH have full-depth measurements (13 April 2005 to 14 October 2007).

\begin{tabular}{lrrrrrr}
\hline Depth [m] & \multicolumn{5}{c}{ EB1 } & \multicolumn{3}{c}{ EBH } \\
& $T\left[{ }^{\circ} \mathrm{C}\right]$ & $S[\mathrm{psu}]$ & $\rho\left[\mathrm{kg} / \mathrm{m}^{3}\right]$ & $T\left[{ }^{\circ} \mathrm{C}\right]$ & $S[\mathrm{psu}]$ & $\rho\left[\mathrm{kg} / \mathrm{m}^{3}\right]$ \\
\hline 220 & $17.22 \pm 0.45$ & $36.44 \pm 0.10$ & $1027.535 \pm 0.040$ & $15.02 \pm 0.83$ & $36.07 \pm 0.14$ & $1027.761 \pm 0.079$ \\
500 & $12.07 \pm 0.15$ & $35.63 \pm 0.03$ & $1029.293 \pm 0.013$ & $11.61 \pm 0.42$ & $35.59 \pm 0.06$ & $1029.354 \pm 0.041$ \\
760 & $8.70 \pm 0.17$ & $35.22 \pm 0.04$ & $1030.770 \pm 0.011$ & $8.91 \pm 0.23$ & $35.28 \pm 0.04$ & $1030.780 \pm 0.021$ \\
1000 & $7.02 \pm 0.14$ & $35.12 \pm 0.04$ & $1032.051 \pm 0.015$ & $7.52 \pm 0.15$ & $35.22 \pm 0.04$ & $1032.046 \pm 0.016$ \\
1260 & $6.22 \pm 0.19$ & $35.18 \pm 0.03$ & $1033.389 \pm 0.013$ & $6.60 \pm 0.12$ & $35.26 \pm 0.03$ & $1033.390 \pm 0.016$ \\
1500 & $5.32 \pm 0.15$ & $35.16 \pm 0.02$ & $1034.587 \pm 0.014$ & $5.52 \pm 0.10$ & $35.193 \pm 0.008$ & $1034.583 \pm 0.012$ \\
1760 & $4.51 \pm 0.09$ & $35.09 \pm 0.01$ & $1035.828 \pm 0.007$ & $4.66 \pm 0.09$ & $35.120 \pm 0.009$ & $1035.824 \pm 0.008$ \\
2000 & $3.99 \pm 0.06$ & $34.053 \pm 0.008$ & $1036.944 \pm 0.004$ & $4.04 \pm 0.08$ & $35.061 \pm 0.008$ & $1036.946 \pm 0.006$ \\
2500 & $3.25 \pm 0.03$ & $34.986 \pm 0.003$ & $1039.232 \pm 0.003$ & $3.24 \pm 0.03$ & $34.984 \pm 0.003$ & $1039.231 \pm 0.003$ \\
\hline
\end{tabular}

At $220 \mathrm{~m}$, variability in temperature, salinity, and density at EB1 is smaller than that at $\mathrm{EBH}$ by $0.38^{\circ} \mathrm{C}, 0.04$, and $0.04 \mathrm{~kg} / \mathrm{m}^{3}$, respectively. In particular, at $220 \mathrm{~m} \mathrm{rms}$ density fluctuations are $\pm 0.04 \mathrm{~kg} / \mathrm{m}^{3}$ at EB 1 and $\pm 0.08 \mathrm{~kg} / \mathrm{m}^{3}$ at $\mathrm{EBH}$ (Fig. 8c). Temperature at EB1 exhibits maximum variability of $\pm 0.45^{\circ} \mathrm{C}$ at the surface, with a local minimum of $0.15^{\circ} \mathrm{C}$ at ca. $900 \mathrm{~m}$, and a local maximum of $0.2^{\circ} \mathrm{C}$ at ca. $1300 \mathrm{~m}$. Temperature and salinity at EBH display maximum variability of $\pm 0.95^{\circ} \mathrm{C}$ and \pm 0.16 respectively at the surface $(120 \mathrm{~m})$. At mid-depths, maximum variability differences between EB1 and EBH are found at ca. $1300 \mathrm{~m}$, where temperature and salinity variability at EB1 exceeds that at $\mathrm{EBH}$, as a result of the deep-reaching anomalies shown in Figs. 3 and 4. However, there is no difference in density variability between EB1 and EBH at this depth level, indicating that even though temperature and salinity vary more at EB1, their variations are density-compensated such that there is no stronger signal in density at EB1. At both sites, the vertical distribution of rms variability in temperature is similar to that in salinity, with both properties fluctuating in-phase (Fig. 8a and $b$ ).

\section{Transport variability}

We now investigate how the differences between the density fluctuations at EB1 and EBH impact the estimates of basin-wide integrated transports. Unless otherwise noted, all the transport time series discussed here are 10-day lowpass filtered, in order to keep valid the assumption of transport compensation required for the computation of $\psi_{\text {MAX }}(t)$ (Kanzow et al., 2007). Results for EB1 are shown only after April 2005, when measurements at EB1 covered the entire water column. A major difference between EB1 and $\mathrm{EBH}$ is that $T_{\mathrm{AMOC}}^{\mathrm{EB} 1}$ (Fig. 9) contains less energy at daily to weekly periods than does $T_{\text {AMOC }}^{\mathrm{EBH}}$ (Fig. 10), consistent with the density observations (Figs. 3 and 5). Both $T_{\text {AMOC }}^{\mathrm{EB} 1}$ and
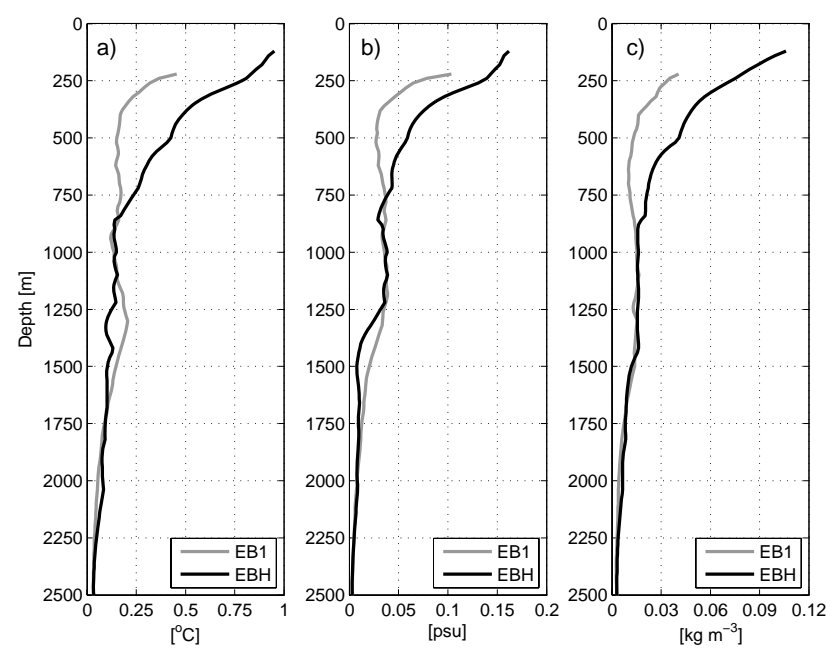

Fig. 8. Standard deviation of (a) temperature, (b) salinity and (c) in-situ density at each depth level between the surface and $2500 \mathrm{~m}$ for EB1 (gray lines) and EBH (black lines). The standard deviation is computed for the period when both EB1 and EBH have full-depth measurements (13 April 2005 to 14 October 2007).

$T_{\text {AMOC }}^{\text {EBH }}$ exhibit stronger fluctuations in the upper layer (above $1400 \mathrm{~m}$ for $T_{\mathrm{AMOC}}^{\mathrm{EB} 1}$ and above $1000 \mathrm{~m}$ for $T_{\mathrm{AMOC}}^{\mathrm{EBH}}$ ) compared to the deeper layer. Below roughly $1500 \mathrm{~m}$ the fluctuations of $T_{\mathrm{AMOC}}^{\mathrm{EB} 1}$ tend to be stronger than those of $T_{\mathrm{AMOC}}^{\mathrm{EBH}}$. The vertical structure of the profiles is dominated by a first mode-like structure, as there is mostly one zero crossing over the record that is at a constant depth. However, there are exceptions to this pattern, when the vertical structure is more complex and displays two zero crossings. This occurs only during short periods, for instance from the beginning of July to the end of August 2007 for $T_{\mathrm{AMOC}}^{\mathrm{EB} 1}$ (Fig. 9), and from the beginning of August 2007 to the end of September 2007 for $T_{\mathrm{AMOC}}^{\mathrm{EBH}}$ (Fig. 10). 


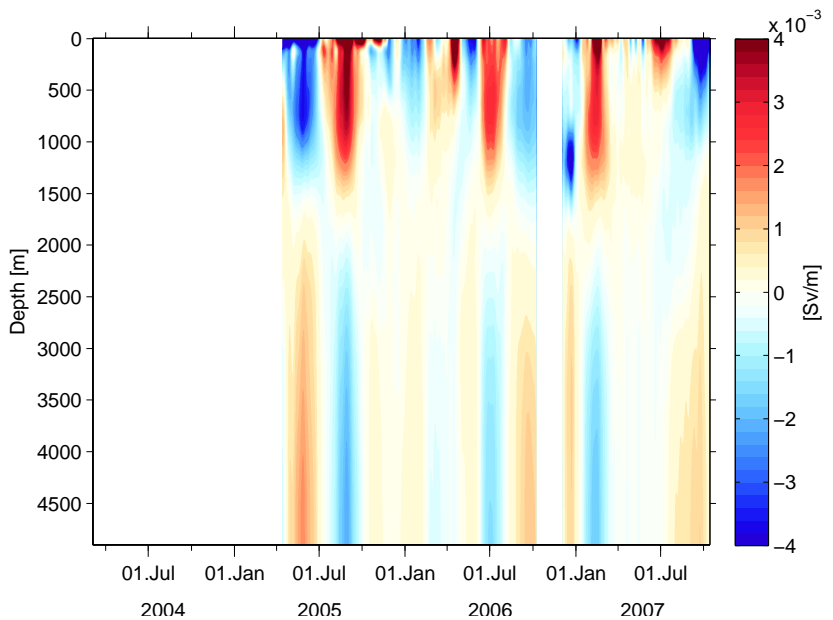

Fig. 9. Anomalies (time mean subtracted) of the transport per unit depth as a function of time and depth, derived from EB1 $\left(T_{\mathrm{AMOC}}^{\mathrm{EB} 1}\right)$ and assuming steady western-boundary conditions. The data are 10-day low-pass filtered.

The first empirical orthogonal function (EOF) modes both of the anomalies about a time-mean vertical profile of $T_{\mathrm{AMOC}}^{\mathrm{EB} 1}$ and of $T_{\mathrm{AMOC}}^{\mathrm{EBH}}$ account for roughly $80 \%$ of the variance each, and both have large vertical shear in the upper ocean (Fig. 11). A closer look reveals, however, that the first modes of $T_{\mathrm{AMOC}}^{\mathrm{EB} 1}$ and $T_{\mathrm{AMOC}}^{\mathrm{EBH}}$ are very different. The zero crossing of the first EOF mode occurs $700 \mathrm{~m}$ deeper for $T_{\mathrm{AMOC}}^{\mathrm{EB} 1}$ $(1740 \mathrm{~m})$ than for $T_{\mathrm{AMOC}}^{\mathrm{EBH}}(1076 \mathrm{~m})$, in agreement with the deep-reaching density anomalies observed at EB1 (Fig. 3). The first EOF mode of $T_{\mathrm{AMOC}}^{\mathrm{EB} 1}$ shows two regions of strong shear above its zero crossing at $1740 \mathrm{~m}$ (above $200 \mathrm{~m}$, possibly representing surface shear modes, Beckman, 1988; and between $1000 \mathrm{~m}$ and $1740 \mathrm{~m}$ ). Between $200 \mathrm{~m}$ and $1000 \mathrm{~m}$ lies a region of weak shear. In contrast, the first mode of $T_{\mathrm{AMOC}}^{\mathrm{EBH}}$ has strong but monotonically decreasing shear between the surface and $1300 \mathrm{~m}$, below its zero crossing at $1000 \mathrm{~m}$; at $1300 \mathrm{~m}$ the shear drops abruptly. In the deep ocean, both $T_{\mathrm{AMOC}}^{\mathrm{EB} 1}$ and $T_{\mathrm{AMOC}}^{\mathrm{EBH}}$ exhibit less shear compared to the upper ocean, but $T_{\mathrm{AMOC}}^{\mathrm{EB} 1}$ has more shear than $T_{\mathrm{AMOC}}^{\mathrm{EBH}}$. Below roughly $2870 \mathrm{~m}$ the amplitude of the first EOF mode of $T_{\mathrm{AMOC}}^{\mathrm{EB} 1}$ is larger than for $T_{\mathrm{AMOC}}^{\mathrm{EBH}}$. As with the first mode, the second EOF mode of $T_{\mathrm{AMOC}}^{\mathrm{EB} 1}$ (accounting for $14 \%$ of the variance) has deeper zero crossings and more shear in the deep ocean compared to the second EOF mode of $T_{\mathrm{AMOC}}^{\mathrm{EBH}}$ (accounting for $15 \%$ of the variance). These differences in vertical structure suggest that the dynamics governing the transport fluctuations are different at EB1 and EBH. Note that the vertical structures of the leading EOF modes of $T_{\mathrm{AMOC}}^{\mathrm{EB} 1}$ and $T_{\mathrm{AMOC}}^{\mathrm{EBH}}$ show no obvious relationship to the vertical water mass structure. Notice also that despite the differences between the EOF modes, the depths of the zero crossings between northward and southward flow are very similar for $T_{\mathrm{AMOC}}^{\mathrm{EB} 1}$ and $T_{\mathrm{AMOC}}^{\mathrm{EBH}}$, occurring on average at $1073 \mathrm{~m}$ $( \pm 44 \mathrm{~m})$ for $T_{\mathrm{AMOC}}^{\mathrm{EB} 1}$ and at $1080 \mathrm{~m}( \pm 40 \mathrm{~m})$ for $T_{\mathrm{AMOC}}^{\mathrm{EBH}}$.

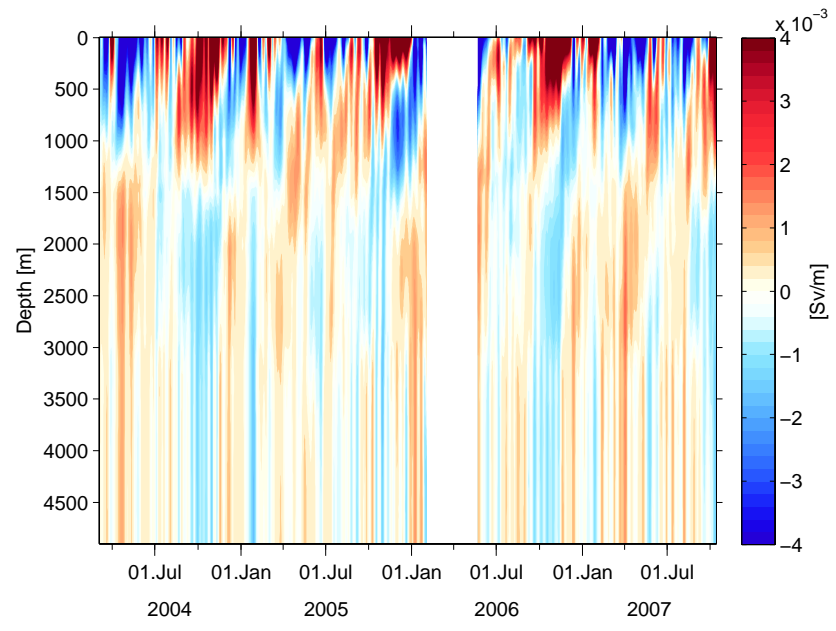

Fig. 10. Anomalies (time mean subtracted) of the transport per unit depth as a function of time and depth, derived from $\mathrm{EBH}\left(T_{\mathrm{AMOC}}^{\mathrm{EBH}}\right)$ and assuming steady western-boundary conditions. The data are 10-day low-pass filtered.

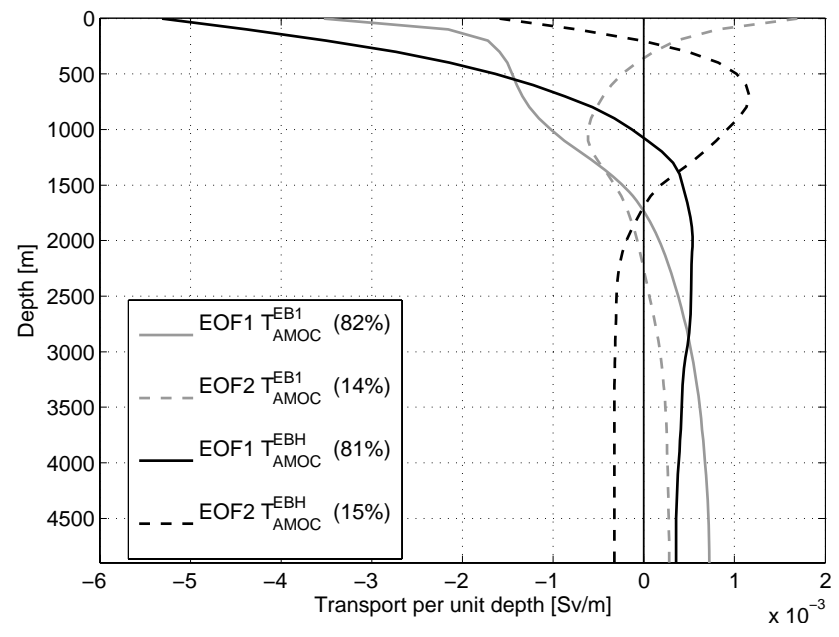

Fig. 11. Vertical structure of the first and second vertical EOF modes of the anomalies (time mean subtracted) of the transport per unit depth profiles derived from EB1 and EBH $\left(T_{\mathrm{AMOC}}^{\mathrm{EB} 1}\right.$ and $T_{\text {AMOC }}^{\text {EBH }}$ ). The modes have been multiplied by the standard deviation of the corresponding principal components. The explained variance by each mode is given in brackets in the figure legend.

We now focus on the fluctuations about the time mean of the overturning transport defined according to Eq. (12) using $\mathrm{EB} 1$ and $\mathrm{EBH}\left(\Psi_{\mathrm{MAX}}^{\mathrm{EB} 1}\right.$ and $\Psi_{\mathrm{MAX}}^{\mathrm{EBH}}$, Fig. 12). The maximum anomaly of $\Psi_{\mathrm{MAX}}^{\mathrm{EB} 1}$ is $4.7 \mathrm{~Sv}$ on 29 August 2005 , corresponding to the strongest negative density anomaly event (Fig. 3), while the minimum anomaly is $-4 \mathrm{~Sv}$ on 29 May 2005, corresponding to the strongest positive density anomaly event (Fig. 3). This yields a maximum transport range of almost $9 \mathrm{~Sv}$ in $\Psi_{\mathrm{MAX}}^{\mathrm{EB} 1}$. The maximum anomaly of $\Psi_{\mathrm{MAX}}^{\mathrm{EBH}}$ is $5.9 \mathrm{~Sv}$ on 14 October 2007 , and the minimum anomaly is $-6.3 \mathrm{~Sv}$ on 3 April 2007, giving a transport range of $12.2 \mathrm{~Sv}$ in $\Psi_{\mathrm{MAX}}^{\mathrm{EBH}}$. 


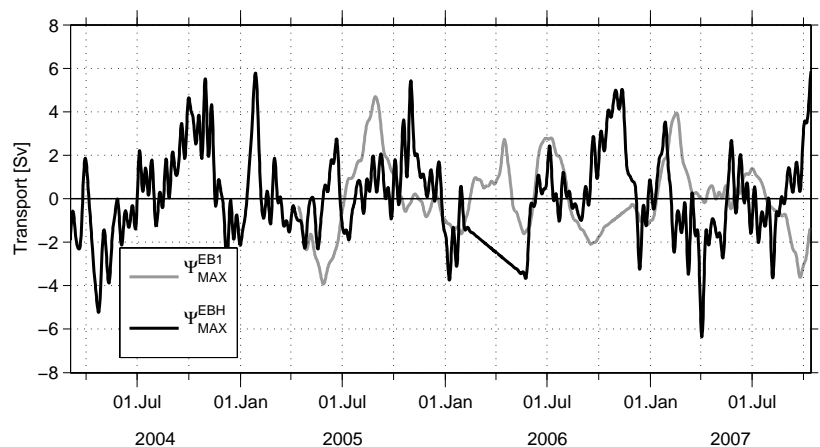

Fig. 12. 10-day low-pass filtered anomalies of the eastern-boundary contribution to the AMOC at $26.5^{\circ} \mathrm{N}$ as derived form $\mathrm{EB} 1\left(\Psi_{\mathrm{MAX}}^{\mathrm{EB} 1}\right.$, gray) and $\mathrm{EBH}\left(\Psi_{\mathrm{MAX}}^{\mathrm{EBH}}\right.$, black). Linear interpolation is chosen to fill the time gaps. Positive transports correspond to northward flow.

The 30-month record of the fluctuations of $\Psi_{\mathrm{MAX}}^{\mathrm{EB} 1}$ has a standard deviation of $\pm 1.7 \mathrm{~Sv}$, and the 42 month record of $\Psi_{\mathrm{MAX}}^{\mathrm{EBH}}$ has a standard deviation of $\pm 2 \mathrm{~Sv}$ (Fig. 12). The integral time scale, obtained by integrating the autocorrelation function out to the first zero-crossing, is 24 days for $\Psi_{\mathrm{MAX}}^{\mathrm{EB} 1}$ and 22 days for $\Psi_{\mathrm{MAX}}^{\mathrm{EBH}}$, resulting in 38 degrees of freedom (dof) in our time series of $\Psi_{\mathrm{MAX}}^{\mathrm{EB} 1}$ and 62 dof in our (longer) time series of $\Psi_{\mathrm{MAX}}^{\mathrm{EBH}}$. Thus, there are 15 and 18 effectively independent measurements per year for $\Psi_{\mathrm{MAX}}^{\mathrm{EB} 1}$ and $\Psi_{\mathrm{MAX}}^{\mathrm{EBH}}$ respectively. If we assume measurement errors negligible, we could resolve year-to-year changes of $0.6 \mathrm{~Sv}$

$$
\begin{aligned}
& \left(\left[\left(1.7^{2} / 15 \cdot 2\right)\right]^{1 / 2}\right) \text { for } \Psi_{\mathrm{MAX}}^{\mathrm{EB} 1} \text { and } 0.6 \mathrm{~Sv}\left(\left[\left(1.9^{2} / 18 \cdot 2\right)\right]^{1 / 2}\right) \\
& \text { for } \Psi_{\mathrm{MAX}}^{\mathrm{EBH}}
\end{aligned}
$$

Although the variability of $\Psi_{\mathrm{MAX}}^{\mathrm{EB} 1}$ and $\Psi_{\mathrm{MAX}}^{\mathrm{EBH}}$ differs by only $0.3 \mathrm{~Sv}$ in rms, their frequency distribution displays markedly different characteristics (Fig. 13). Both $\Psi_{\mathrm{MAX}}^{\mathrm{EB} 1}$ and $\Psi_{\mathrm{MAX}}^{\mathrm{EBH}}$ have dominant variance at low frequencies, and for periods longer than 50 days the spectra of the two time series are not significantly different. However, for periods shorter than 50 days, the variance of $\Psi_{\mathrm{MAX}}^{\mathrm{EB} 1}$ drops rapidly, such that for periods between 10 and 50 days the variance of $\Psi_{\mathrm{MAX}}^{\mathrm{EB} 1}$ is a factor of 10 smaller than that of $\Psi_{\mathrm{MAX}}^{\mathrm{EBH}}$. Of the spectral peaks in $\Psi_{\mathrm{MAX}}^{\mathrm{EBH}}$, only the one around 13 days is clearly significant at the $95 \%$ confidence level; this peak is associated with the 13-day density variations that are coherent down to $3500 \mathrm{~m}$ (Sect. 4, Fig. 7). A cross-correlogram of 50-day low-pass filtered time series of $\Psi_{\mathrm{MAX}}^{\mathrm{EB} 1}$ and $\Psi_{\mathrm{MAX}}^{\mathrm{EBH}}$ fails to show significant correlation at any time lag between the two time series at the 95\% confidence level (not shown), implying that we cannot identify potential westward signal propagation between the two sites through long Rossby waves.

The results presented here show that there is little agreement between the transports estimates from EB1 and EBH. There are considerable differences between EB1 and EBH in terms of amplitude, vertical structure and frequency distri-

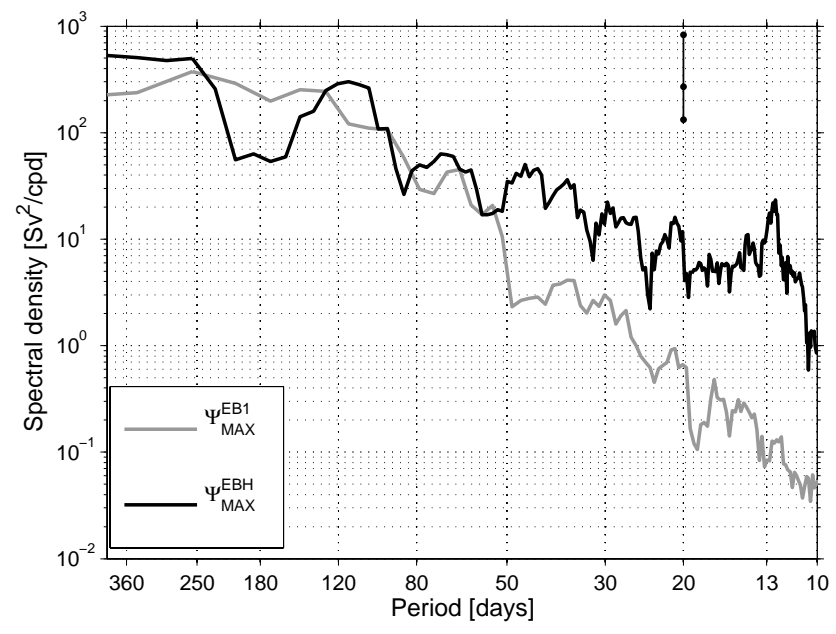

Fig. 13. Power spectra of the 10-day low-pass filtered anomalies of the eastern-boundary contribution to the AMOC at $26.5^{\circ} \mathrm{N}$ as derived form EB1 ( $\Psi_{\mathrm{MAX}}^{\mathrm{EB} 1}$, gray) and $\mathrm{EBH}\left(\Psi_{\mathrm{MAX}}^{\mathrm{EBH}}\right.$, black). The vertical line in the upper right corner represents the $95 \%$ confidence interval. The power spectrum is computed following Percival and Walden, 1993.

bution of the resulting mid-ocean geostrophic transport fluctuations. This implies that density fluctuations at the eastern boundary of the $26.5^{\circ} \mathrm{N}$ section need to be monitored across the continental slope. Mechanisms that are unrelated to the AMOC (such as basin-interior eddies) appear to influence strongly the density variability at EB1 on the time scales under consideration. In addition, the tall mooring EB1 is too far offshore to detect potential boundary waves and/or wind-induced processes near the coast (such as upwelling or Ekman pumping). We conclude that only the EBH data set should be used to compute the eastern-boundary density contribution to the AMOC. Analyses in the remaining part of the paper will therefore rely entirely on EBH.

\section{Seasonal variability}

We now investigate the seasonal cycle in the density anomalies. Given that the observations span 42 months, the seasonal cycle represents the longest period that we can analyze with confidence. The monthly averages of in-situ density at selected depths levels (Fig. 14) show that there is a pronounced seasonal variability in density right at the continental slope off northwest Africa at $26.5^{\circ} \mathrm{N}$. Maximum values occur during spring (April/May) and minimum values during autumn (October/November). The seasonal cycle is coherent throughout the upper ocean and is surprisingly deep-reaching as it can be observed up to a depth of $1400 \mathrm{~m}$. For all depth levels between $100-1400 \mathrm{~m}$, the seasonal cycle is statistically significant. 

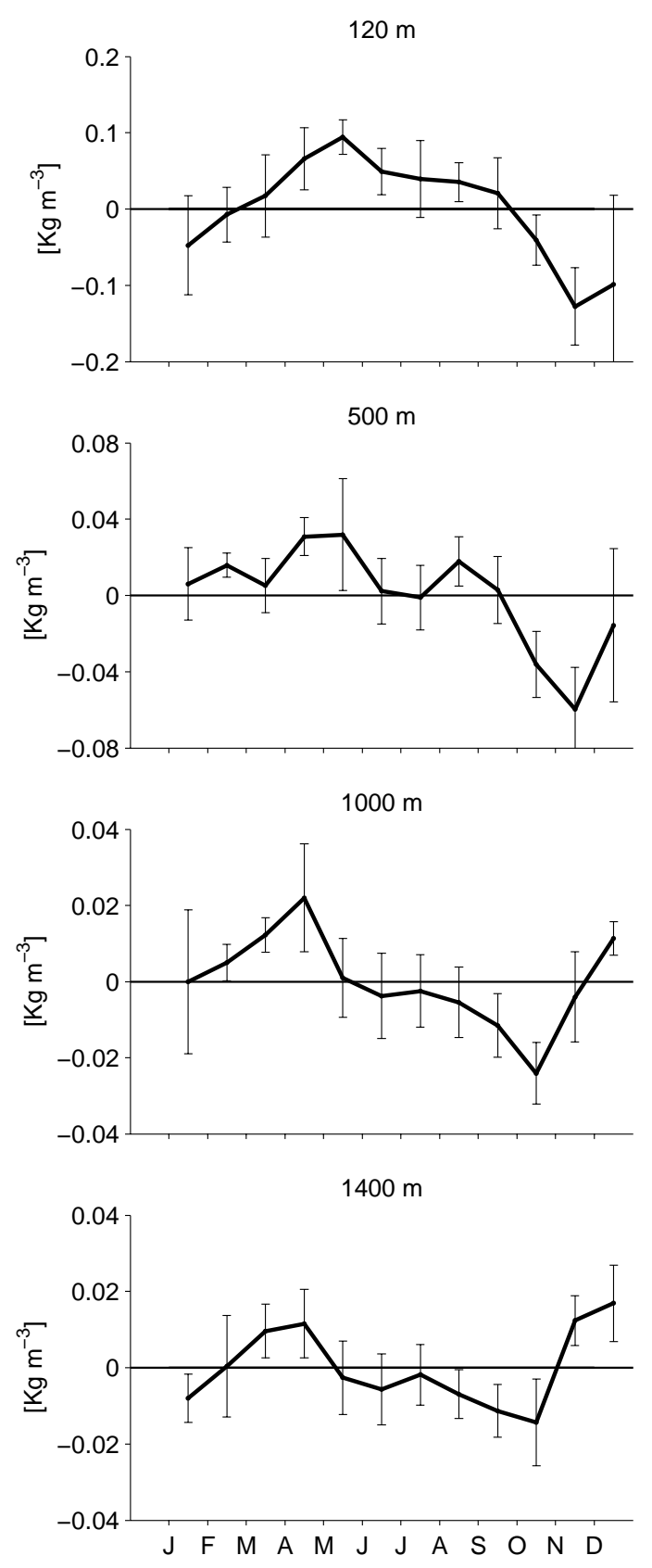

Fig. 14. Monthly-mean in-situ density anomaly at EBH at selected depths. The bars indicate standard deviations of the monthly means. Note the change of the density scale.

As a result of the deep reaching seasonal cycle in density, there is also a pronounced seasonal cycle in the easternboundary contribution to the AMOC, as monthly means of the anomalies of $\Psi_{\mathrm{MAX}}^{\mathrm{EBH}}$ show (Fig. 15). The observed seasonal density changes drive an enhanced southward upper mid-ocean flow in spring (April), resulting in a minimum in the $\Psi_{\mathrm{MAX}}^{\mathrm{EBH}}$, and vice-versa in autumn (October). The amplitude of the seasonal cycle of $\Psi_{\mathrm{MAX}}^{\mathrm{EBH}}$ is $5.2 \mathrm{~Sv}$ peak-to-peak,

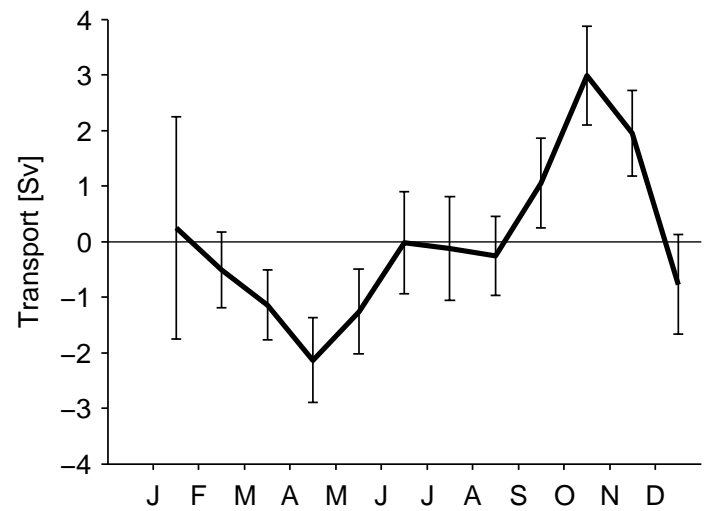

Fig. 15. Monthly-mean anomalies of the eastern-boundary contribution to the AMOC at $26.5^{\circ} \mathrm{N}\left(\Psi_{\mathrm{MAX}}^{\mathrm{EBH}}\right)$. The bars show standard deviations of the monthly means.

with the peak in April being statistically different from the peak in October.

\section{Discussion}

The largest density anomalies at the eastern-boundary continental slope (EBH) at $26.5^{\circ} \mathrm{N}$ are found in the upper $500 \mathrm{~m}$ of the water column, but they are often coherent down to $1400 \mathrm{~m}$. The densities at EBH show 13-day fluctuations that are apparent down to $3500 \mathrm{~m}$. The possible mechanism driving the 13-day density variability is not clear. Spectra of the wind field do not show any sign of dominant winddriven forcing at this period. It can be expected that this phenomenon is associated with sea surface height anomalies; therefore a possible way to investigate the spatial scales associated with the 13-day period might be via satellite altimeter data. However, aliasing due to the insufficient temporal resolution (the Jason altimeter has a repeat cycle of 10 days) will make such an analysis problematic. The closeness of the 13-day fluctuations to the fortnightly tidal periods could point to a tidal origin of this signal. However, fortnightly tidal fits applied to the EBH densities give rather different results for different depth levels (not shown), suggesting that the 13-day fluctuations are not regular enough to be tidal oscillations. It could be that the 13-day period is associated to variability induced by the eddy shedding south of the Canary Islands. However, the previously reported eddy generation sites are mostly south of Gran Canaria (distant from the shallower measurements at EBH) and subsequently the eddies tend to propagate downstream to the west (e.g., Sangrà et al., $2005,2009)$. Therefore it seems unlikely that they can be responsible for the density variability observed at EBH. Furthermore, the density fluctuations we observe are coherent over a large depth range of up to $3500 \mathrm{~m}$, while the maximum depth associated with anomalies of eddies shed by the Canary islands is roughly $1000 \mathrm{~m}$ (Piedeleu et al., 2009). Alternatively, the geometry of the semi-enclosed basin south of 
the Canary Island where we take our measurements might play a role in the generation of 13-day basin modes excited by stochastic wind forcing.

The temporal variability and the vertical structure of the transports derived from EB1 and EBH have different characteristics. The transports derived from EB1 show much less energy at periods shorter than 50 days, compared to the transports derived from EBH. The leading EOF transport modes show that the vertical shear of the transport arising from EB1 and EBH is especially different in the upper $1000 \mathrm{~m}$. This points to different dynamics governing the density fluctuations at EB1 and EBH. Kanzow et al. (2009b) show that the local wind forcing is very different, and much weaker, at EB1 than EBH. Hence, local coastal wind forcing appears to play an important role in setting the variability at EBH. At EB1, the deep-reaching density anomalies may be linked to mesoscale eddies associated with the open ocean circulation. Contrary to the original planning (Marotzke et al., 2002), measurements at EB1 and EBH cannot serve as a backup for each other: densities need to be measured right at the continental slope to compute the eastern boundary density contribution to the AMOC.

Lee and Marotzke (1998) had proposed a decomposition of the meridional overturning circulation into three components, (i) the Ekman transport and its depth-independent compensation, (ii) the geostrophic shear associated with east to west density differences, and (iii) the contribution from barotropic velocities over sloping bathymetry (external mode). The Ekman contribution is not part of this study, and the eastern boundary contribution to the shear component is covered by the density measurements. But how about the external mode? Hirschi and Marotzke (2007) found in an eddy-permitting model of the Atlantic that the external mode mostly affected the time mean flow but not the temporal variability. They noticed that the external mode contribution to the AMOC becomes sizeable for large bottom velocities. For small bottom velocities the strength and vertical structure of the simulated AMOC (including the external mode) could be reconstructed reliably from eastern and western boundary densities as we attempted in this study. At $26.5^{\circ} \mathrm{N}$ (if at all) we expect the external mode to be relevant in the western boundary current system where large bottom velocities both in upper ocean (Antilles Current) and the deep western boundary current can occur (Johns et al., 2008). The direct current meter measurements across the western boundary continental slope are used to capture this contribution. At the eastern boundary, observations by Knoll et al. (2002) in the Lanzarote Passage at $29^{\circ} \mathrm{N}$ show that the mean bottom velocity close to $1200 \mathrm{~m}$ only amounts to $-1.0 \mathrm{~cm} / \mathrm{s}$. In addition, at the deep part of EB1 the temperature fluctuations are of $\mathrm{O}\left(10^{-2}{ }^{\circ} \mathrm{C}\right)$ (Fig. 4, Sect. 4), therefore it can be expected that the bottom currents are small near EB1. Thus, our reconstruction of the AMOC from densities at the eastern boundary is unlikely to be affected significantly by a possible misrepresentation of the external mode.
The 10-day low-pass filtered 42-month long record of the eastern boundary contribution to the AMOC at $26.5^{\circ} \mathrm{N}$, $\Psi_{\mathrm{MAX}}^{\mathrm{EBH}}$, has a temporal standard deviation of $\pm 2 \mathrm{~Sv}$. Kanzow et al. (2009b) show that the overall AMOC variability is $\pm 4.8 \mathrm{~Sv}$ and that the western boundary contribution of the mid-ocean section to the AMOC varies by $\pm 2.3 \mathrm{~Sv}$. The latter indicates that the western and eastern boundaries of the mid-ocean section contribute to the AMOC variability by roughly the same amount. This result contradicts earlier findings by Longworth (2007), who found from historical CTD measurements that the eastern boundary contribution was only half of that from the western boundary. However, the total western-boundary transport contribution to the AMOC also includes variability of the Gulf Stream and is hence significantly larger than that from the eastern boundary.

We find a pronounced deep-reaching seasonal cycle in eastern-boundary density, with maximum positive density anomalies in spring and negative ones in autumn, which are coherent between $100 \mathrm{~m}$ and $1400 \mathrm{~m}$. These anomalies drive anomalous southward upper mid-ocean flow in spring, implying maximum reduction of the AMOC, and anomalous northward upper mid-ocean flow in autumn, implying maximum strengthening of the AMOC. The eastern boundary causes a peak-to-peak seasonal cycle of the AMOC of $5.2 \mathrm{~Sv}$, clearly dominating the peak-to-peak seasonal cycle of the total AMOC of 6.7 Sv (Kanzow et al., 2009b). This dominant influence is surprising and arises because western boundary transports do not display such a clear seasonal cycle when isolated in a similar fashion. The peak-to-peak amplitudes of the seasonal cycles of the remaining contributing components are $3.0 \mathrm{~Sv}, 2.1 \mathrm{~Sv}$, and $3.9 \mathrm{~Sv}$ for $T_{\mathrm{GS}}, T_{\mathrm{EK}}$, and the western-boundary contribution of the mid-ocean section, respectively. Therefore, the rms of the seasonal amplitudes of all the components is $7.5 \mathrm{~Sv}$, thus slightly larger than the 6.7 Sv of the total AMOC. This indicates that a small degree of compensation occurs between the components on seasonal time scales.

A detailed analysis of the mechanisms driving the seasonal density fluctuations is subject of ongoing work and is beyond the scope of this paper. We do, however, offer a preliminary analysis here. Several authors reported seasonal anomalies of the eastern boundary current system off Northwest Africa based on mooring-based measurements and hydrographic observations. A strong northward current during autumn close to the African shelf in the 1300 m deep channel between Lanzarote and Africa at $29^{\circ} \mathrm{N}$ was observed (Knoll et al., 2002; Hernández-Guerra et al., 2003). Knoll et al. (2002) found maximum southward flow in the upper $200 \mathrm{~m}$ in the middle of the channel between Lanzarote and Africa during spring. The seasonal northward transport in the Canary Current system is consistent with the anomalous northward transports (and minimum in in-situ density) we find in October (Fig. 15). The phase of maximum southward flow during spring reported by Knoll et al. (2002) is 
consistent with the southward transports (and maximum in in-situ density) we find in April (Fig. 15). This suggests a link with the variability we find in $\Psi_{\mathrm{MAX}}^{\mathrm{EBH}}$ but further analysis needs to be done on the variability of the eastern boundary current. A possible way to investigate this would be to compare the available current-meter time series at the Lanzarote passage (Hernández -Guerra et al., 2003) with our observations of $\Psi_{\mathrm{MAX}}^{\mathrm{EBH}}$. If good agreement is found, this would allow expanding the eastern-boundary AMOC time series back in time to January 1997 (when the current-meter measurements were initiated). This might be of potential importance for the re-construction of the AMOC before the start of the RAPID/MOCHA array in April 2004.

The Moroccan coastal upwelling undergoes seasonal changes induced by the coast-parallel trade winds. The band between $25^{\circ} \mathrm{N}$ and $43^{\circ} \mathrm{N}$ along the African coast exhibits strongest coastal upwelling during summer and autumn (e.g., Wooster et al., 1975; Mittelstaedt et al., 1983). We observe maximum densities in April/May, two months earlier than the maximum upwelling occurs. Also coastal upwelling is thought to bring waters from 200 or $300 \mathrm{~m}$ depth to the surface. In contrast, our analysis suggests coherent seasonal density changes down to $1400 \mathrm{~m}$. For these reasons coastal upwelling is unlikely to be the direct driver of the seasonal density and transport cycles. Instead, the vertical structure suggests a first baroclinic mode as a result of the displacement of the density surfaces induced by the wind stress curl. A preliminary analysis of the QuikSCAT-based SCOW (Scatterometer Climatology of Ocean Winds) seasonal wind stress curl climatology (Risien and Chelton, 2008) reveals a pronounced seasonal cycle in eastern boundary wind stress curl, which leads the density anomaly by roughly 90 degrees or 3 months (Fig. 16). The out-of-phase relationship is plausible, as uplifting of the density surfaces should prevail during the winter phases of enhanced cyclonic wind curl anomalies. Therefore maximum positive density anomalies can be expected in spring, when the transition from cyclonic to anti-cyclonic wind stress curl anomalies takes place. The summer period of anti-cyclonic wind stress curl then should lead to the observed maximum negative density anomalies in autumn as a result of the maximum depression of the density surfaces. The SCOW data set exhibits limitations in resolving the wind curl near the coast close to the mooring locations and needs to be further investigated.

\section{Conclusions}

Based on 3.5 years of moored temperature and salinity data at the eastern boundary of the Atlantic at $26.5^{\circ} \mathrm{N}$ from a tall mooring (EB1) located at the base of the continental rise $\left(24^{\circ} \mathrm{W}\right)$ and an array of small moorings $(\mathrm{EBH})$ distributed across the continental slope up to the Moroccan shelf $\left(14^{\circ} \mathrm{W}\right)$, we find:

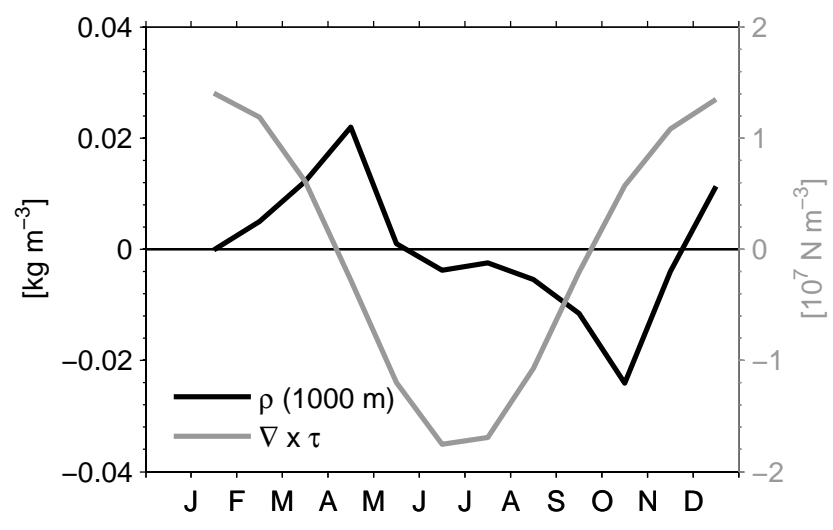

Fig. 16. Monthly means of in-situ density anomaly at $1000 \mathrm{~m}$ from EBH (black), and seasonal cycle of wind stress curl $(\nabla \times \tau)$ anomaly at $27^{\circ} 7.5^{\prime} \mathrm{N}, 15^{\circ} 22.5^{\prime} \mathrm{W}$ (about $200 \mathrm{~km}$ away from the position of the shallowest mooring at EBH), based on the SCOW climatology (Risien and Chelton, 2008; gray).

- Density anomalies at EBH are often coherent down to $1400 \mathrm{~m}$; 13-day density fluctuations even reach down to $3500 \mathrm{~m}$. This vertical coherence confirms the validity of the sampling strategy at $\mathrm{EBH}$, including the merging of the profiles.

- There are significant transports between EB1 and EBH, so contrary to the original planning, measurements at EB1 cannot serve as backup for EBH. Density needs to be observed right at the continental slope as part of an AMOC monitoring strategy.

- Eastern-boundary density variations contribute \pm 2 Sv rms AMOC variability, similar to the contribution from the western boundary (east of the Bahamas) to the mid-ocean geostrophic component of the AMOC.

- The seasonal cycle in density at the eastern boundary is coherent between $100 \mathrm{~m}$ and $1400 \mathrm{~m}$, with maximum positive and negative density anomalies in spring and autumn, respectively. Resulting is a minimum AMOC in spring and a maximum AMOC in autumn, with a peak-to-peak amplitude of the seasonal cycle of $5.2 \mathrm{~Sv}$ caused by the eastern boundary, which dominates the 6.7 Sv seasonal cycle of the total AMOC.

- At present the long-term contribution of easternboundary density variability to the AMOC is uncertain. The annual cycle at the eastern boundary, however, is larger than expected. This may mean that on longer time scales the contribution from eastern-boundary densities to the AMOC could be significant. Long-term sustained density measurements at $\mathrm{EBH}$ are necessary to quantify the role of eastern-boundary densities on AMOC changes at $26.5^{\circ} \mathrm{N}$ on inter-annual and longer time scales. 
Acknowledgements. We thank the captains and crews of the research vessels Discovery and Poseidon, and the UKORS mooring team. The mooring operations have been funded by NERC RAPID. We would like to thank Zoltán Szuts for providing valuable comments on the manuscript. This work was supported by the Max Planck Society and the International Max Planck Research School on Earth System Modelling.

The service charges for this open access publication have been covered by the Max Planck Society.

Edited by: M. Hecht

\section{References}

Baringer, M. O. and Larsen, J. C.: Sixteen years of Florida Current transport at $27^{\circ} \mathrm{N}$, Geophys. Res. Lett., 28(16), 3179-3182, 2001.

Baringer, M. O., Johns, W. E., Meinen, C. S., Shoosmith, D., and Bryden, H. L.: On the Structure of Florida Current Variability. Poster presentation at the Rapid Climate Change 2008 annual meeting, Cambridge, UK, online available at: http://www.noc. soton.ac.uk/rapid/sci/viewabs1.php?keyword1=gwa806, 2008.

Beckmann, A.: Vertical structure of midlatitude mesoscale instabilities, J. Phys. Oceanogr., 18, 1354-1371, 1988.

Bryden, H. L., Longworth, H. R., and Cunningham, S. A.: Slowing of the Atlantic meridional overturning circulation at $25^{\circ} \mathrm{N}$, Nature, 438, 655-657, doi:10.1038/nature04385, 2005.

Cunningham, S. A., Kanzow, T., Rayner, D., Baringer, M. O., Johns, W. E., Marotzke, J., Longworth, H. R., Grant, E. M., Hirschi, J. J.-M., Beal, L. M., Meinen, C. S., and Bryden, H. L.: Temporal variability of the Atlantic meridional overturning circulation at $26.5^{\circ} \mathrm{N}$, Science, 317, 935-938, 2007.

Hernández-Guerra, A., Aristegui, J., Canton, M., and Nykjaer, L.: Phytoplankton pigment patterns in the Canary Islands area as determined using Coastal Zone Colour Scanner data, Int. J. Remote Sens., 14, 1431-1437, 1993.

Hernández-Guerra, A., Fraile-Nuez, E., Borges, R., López-Laatzen, F., Véllez-Belchi, P., Parrilla, G., and Müller, T.: Transport variability in the Lanzarote passage (eastern boundary current of the North Atlantic Subtropical Gyre), Deep-Sea Res. I, 50, 189-200, 2003.

Hall, M. M. and Bryden, H. L.: Direct estimates and mechanisms of ocean heat transport, Deep Sea Res., 29(3A), 339-359, 1982.

Hirschi, J., Baehr, J., Marotzke, J., Stark, J., Cunningham, S. A., and Beismann, J. O.: A monitoring design for the Atlantic meridional overturning circulation, Geophys. Res. Lett., 30(7), 1413, doi:10.1029/2002GL016776, 2003.

Hirschi J. J.-M. and Marotzke, J.: Reconstructing the meridional overturning circulation from boundary densities and the zonal wind stress, J. Phys. Oceanogr., 37(3), 743-763, 2007.

Johnson, H. L. and Marshall, D. P.: Localization of abrupt change in the North Atlantic thermohaline circulation, Geophys. Res. Lett., 29(6), 1083, doi:10.1029/2001GL014140, 2002.

Johnson, H. L. and Marshall, D. P.: Global teleconnections of meridional overturning circulation anomalies, J. Phys. Oceanogr., 34, 1702-1722, 2004.

Johns, W. E., Kanzow, T., and Zantopp, R.: Estimating ocean transports with dynamic height moorings: An application in the
Atlantic deep western boundary current, Deep-Sea Res. I, 52, 1542-1567, 2005.

Johns, W. E., Beal, L. M., Baringer, M. O., Molina, J., Cunningham, S. A., Kanzow, T., and Rayner, D.: Variability of shallow and deep western boundary currents off the Bahamas during 2004 2005: First results from the $26^{\circ}$ N RAPID-MOC array, J. Phys. Oceanogr., 38, 605-623, 2008.

Kawase, M.: Establishment of mass-driven abyssal circulation, J. Phys. Oceanogr., 17, 2294-2317, 1987.

Kanzow, T., Send, U., Zenk, W., Chave, A. D., and Rhein, M.: Monitoring the integrated deep meridional flow in the tropical North Atlantic: Long-term performance of a geostrophic array, DeepSea Res. I, 53, 528-546, 2006.

Kanzow, T., Cunningham, S. A., Rayner, D., Hirschi, J. J.-M, Johns, W. E. , Baringer, M. O., Bryden, H. L., Beal, L. M., Meinen, C. S., and Marotzke, J.: Observed flow compensation associated with the MOC at $26.5^{\circ} \mathrm{N}$ in the Atlantic, Science, 317, 938-941, 2007.

Kanzow, T., Hirschi, J. J.-M, Meinen, C. S., Rayner, D., Cunningham, S. A, Marotzke, J., Johns, W. E., Bryden, H. L., Beal, L. M., and Baringer, M. O.: A prototype system for observing the Atlantic Meridional Overturning Circulation - scientific basis, measurement and risk mitigation strategies, and first results, J. Operat. Oceanogr., 1, 19-28, 2008.

Kanzow, T., Johnson, H., Marshall, D., Cunningham, S. A., Hirschi, J. J.-M., Mujahid, A., Bryden, H. L., and Johns, W. E.: Basin-wide integrated volume transports in an eddy-filled ocean, J. Phys. Oceanogr., 39(12), 3091-3110, doi:10.1175/2009JPO4185.1, 2009a.

Kanzow, T., Cunningham, S. A, Johns, W. E., Hirschi, J. J.-M., Marotzke, J., Baringer, M. O., Meinen, C. S., Chidichimo, M P., Atkinson, C., Beal, L. M., Bryden, H. L., and Collins, J.: Seasonal variability of the Atlantic meridional overturning circulation at $26.5^{\circ} \mathrm{N}$, J. Climate, submitted, 2009b.

Knoll, M., Hernández-Guerra, A., Lenz, B., López-Laatzen, F., Machín, F., Müller, T. J., and Siedler, G.: The Eastern Boundary Current System between the Canary islands and the African coast, Deep-Sea Res. II, 49(17), 3427-3440, 2002.

Köhl, A.: Anomalies of meridional overturning: Mechanisms in the North Atlantic, J. Phys. Oceanogr., 35, 1455-1472, 2005.

Larsen, J. C.: Transport and heat flux of the Florida Current at $27^{\circ} \mathrm{N}$ derived from cross-stream voltages and profiling data: theory and observations, Philos. T. Roy. Soc. London, A 338, 169-236, 1992.

Lee, T. and Marotzke, J.: Seasonal cycles of meridional overturning and heat transport of the Indian Ocean, J. Phys. Oceanogr., 28, 923-943, 1998.

Longworth, H. R.: Constraining variability of the Atlantic meridional overturning circulation at $26.5^{\circ} \mathrm{N}$ from historical observations, Ph.D. Thesis, School of Ocean and Earth Science, University of Southampton, Southampton, UK, 198 pp., 2007.

Marotzke, J., Cunningham, S. A., and Bryden, H. L.: Monitoring the Atlantic meridional over-turning circulation at $26.5^{\circ} \mathrm{N}$, Proposal accepted by the Natural Environment Research Council (UK), online available at: http://www.noc.soton.ac.uk/ rapidmoc/, 2002.

Mittelstaedt, E.: The upwelling area off northwest Africa- a description of phenomena related to coastal upwelling, Prog. Oceanogr., 12, 307-331, 1983. 
Percival, D. B. and Walden, A. T.: Spectral analysis for physical applications: Multitaper and conventional univariate techniques, Cambridge University Press, Cambridge, UK, 583 pp., 1993.

Piedeleu, M., Sangrà, P., Sánchez-Vidal, A., Fabrés, J., Gordo, C., and Calafat, A.: An observational study of oceanic eddy generation mechanisms by tall deep-water islands (Gran Canaria), Geophys. Res. Lett., 36, L14605, doi:10.1029/2008GL037010, 2009.

Rayner, D. (ed.): RV Ronald H. Brown Cruise RB0602 and RRS Discovery Cruise D304, Rapid Mooring Cruise March and May 2006, National Oceanography Centre Southampton, Cruise report No. 16, 165 pp., Southampton, UK, 2007.

Risien, C. M. and Chelton, D. B.: A global climatology of surface wind and wind stress fields from eight years of QuikSCAT scatterometer data, J. Phys. Oceanogr., 38, 2379-2413, 2008.

Roemmich, D. and Wunsch, C.: Two transatlantic sections: Meridional circulation and heat flux in the subtropical North Atlantic Ocean, Deep-Sea Res., 32(5), 619-664, 1985.
Sangrà, P., Pelegrí, J. L., Hernández-Guerra, A., Arregui, I., Martín, J. M., Marrero- Díaz, A., Martínez, A., Ratsimandresy, A. W., and Rodríguez-Santana, A.: Life history of an anticyclonic Eddy, J. Geophys. Res., 110, C03021, doi:10.1029/2004JC002526, 2005.

Sangrà, P., Pascual, A., Rodríguez-Santana, A., Machín, F., Mason, E., McWilliams, J. C., Pelegrí, J. L., Dong, C. M., Rubio, A., Arístegui, J., Marrero- Díaz, A., Hernández-Guerra, A., Martínez-Marrero, A., and Auladell, M.: The Canary Eddy Corridor: A major pathway for long-lived eddies in the subtropical North Atlantic, Deep-Sea Res. I, 56, 2100-2114, 2009.

Wooster, W. S., Bakun, A., and McLain, D. R.: The seasonal upwelling cycle along the eastern boundary of the North Atlantic, J. Mar. Res., 34, 131-141, 1976.

Worthington, L. V.: On the North Atlantic Circulation, Vol. 6, The John Hopkins Oceanography Studies, The John Hopkins University Press, 110 pp., 1976. 